ESTUDIOS 


\title{
LA CRUZADA ALBIGENSE Y LA INTERVENCIÓN DE LA CORONA DE ARAGÓN EN OCCITANIA. EL RECUERDO DE LAS CRÓNICAS HISPÁNICAS DEL SIGLO XIII.
}

\author{
por \\ MARTÍ́n ALVIRA CABRer \\ Universidad Complutense de Madrid 1
}

RESUMEN: La destacada participación bispana en los acontecimientos de la Cruzada Albigense (1209-1229) refleja los importantes lazos que durante siglos vincularon la Peninsula lbérica y las tierras occitanas del Mediodía de Francia. Con la excepción de la Canso de la Crozada del poeta navarro Guillermo de Tudela, la memoria bispana de la Cruzada se centró en la derrota y muerte del rey Pedro el Catblico de Aragón en la batalla de Muret (1213). La posición de los autores bispanos tuvo en común la defensa de la ortadoxia del monarca por la vía del ocultamiento del problema cátaro 0 de la justificación por motivos feudales. En Castilla-León, La «memoria bistoriográfica $y$ oficials elaborada por el arzobispo Rodrigo de Toledo se impuso a la avision cruzadista” de otros prelados. Su versión fue asumida en la Corona de Aragón, donde coexistió con una «memoria dinásticas exaltadora de las virtudes caballerescas del rey Pedro. Desde finales del siglo XIII, todos ertos recuerdos bispánicos de la Cruzada Albigense apenas sufririan modificaciones.

Palabras Clave: Edad Media. Cruzada Albigense. España. S. XIII. Historiografía. Corona de Aragón. Occitania. Muret.

ABSTRACT: The conspicuous Hispanic participation in the events of the Albigensian Crusade (1209-1229) reflects the important links that for centuries linked the lberian $P_{e-}$ ninsula and the Occitan lands of southern France. With the exception of the Canso de la Crozada by the Navarrese poet Guillermo of Tudela, Hispanic memory of the

1 Este trabajo fue presentado como conferencia en el Coloquio «Le Cathatisme, nouvelles recherches, nouvelles perspectivesn celebrado en el Centre d'Etudes Cathanes (Carcassonne, Francia) en homenaje al profesor Jean Duvernoy los dias 20 al 22 de agosto de 1998. Agradezco de nuevo aquí a la profesora Anne Brenon la amable invitación que hizo posible mi participación en dicho Coloquio.

Hisponia, LX/3, núm. $206(2000) 947-976$ 
Crusade focussed on the defeat and death of King Pedro the Catbolic of Aragon in the battle of Muret (1213). The pasition of the Hispanic autbors wat characterized by a common defense of the king's ortbodoxy through the suppression of the Catbar heresy, or justification by feudal motives. In Castile-León, the «bistoriograpbical and official account" written by arcbbishop Rodrigo of Toledo was imposed over the acrusading vision of other prelates. His version was taken up in the Crown of Aragon, coexisting with a "dynastic account" that exalts the chivalrous virtues of the king Pedro. From the end of the thirteenth century, all these Hispanic memories of the Albigensian Crusade are bardly modified.

KEY WORDS: Middle Age. Albigensian Crusade. Historiography. Spain. $13^{\text {th }}$ Century. Crown of Aragon. Occitania. Muret.

La Cruzada Albigense (1209-1229), la faceta político-militar de la lucha de la Iglesia Católica contra el Catarismo, tuvo como principales protagonistas a los occitanos (languedocianos, provenzales, gascones, etc.) acusados de herejía y a los cruzados de Francia (Île-de-France y mitad norte del reino) que les combatieron $^{2}$. Sin embargo, el negotium Cbristi fue un acontecimiento de dimensiones europeas en el que participaron gentes de casi todo el Occidente medieval. De todas ellas, pocas jugaron un papel tan activo y decisivo en la «cuestión albigense» como las venidas de la Península Ibérica.

\section{ESPANHA Y «OCCITANIA» ANTES Y DURANTE LA CRUZADA ALBIGENSE}

La presencia hispana en las tierras de la lengua de Oc durante la Alta y la Plena Edad Media fue consecuencia logica de los vínculos geográficos, culturales e históricos entre ambas vertientes de los Pirineos desde tiempos antiguos ${ }^{3}$. La conciencia viva de un pasado común y de unas afinidades socio-culturales y político-administrativas entre Hispania y la Narbonense o Galia Gótica explica que durante casi todos los siglos medievales muchas de las tierras occitanas fueran consideradas una parte de Espanna ${ }^{4}$. Después del año 1000 las relaciones

\footnotetext{
2 La bibliografia sobre la Cruzada Albigense y el Catarismo es muy amplia, por lo que nos remitimos a las fuentes $y$ obras citadas.

3 Según BONNASSIE, Pierre: «Il faut écarter délibérément l'idée reçue d'une frontière sur les Pyrenées. Le Pyrenées sont toujours au Moyen Âge soir endeçà soit au-delà de frontières dont la nature est multiple», en SENAC, Ph. (dir.), Frontières et espaces pyrenéens au Moyen Âge, CrePF, Perpignan, 1992, Intr., p. 13. «Entre la France et l'Espagne, au nord-est du royaume d'Atagon et de Catalogne, il n'y avait pas de Pyrénées», LE GOFF, J., Saint Louis, París, Gallimard, 1996, p. 255.

4 E Galiat quier dezir tanto commo Francias. Otrossy dize que son quatro Galias: Gallia Comata e Galia Belgica e Galia Çisalpina e Gallia Gotica (...) Gallia Gotica dizen por que los godos tomaron aquella tierra, Don Juan Manuel, Crónica abreviada (1320-1324), ed. BleCua, J.M.: Don Juan Manuel. Obras Completas, 2 vols., Madrid, Gredos, I982-I983, vol. Il, cap. CCXXX, p. 790. Demas es en esta Espanna la Gallia Gothica que es en la prouincia de Narbona [Narbonne] dessuno con las cibdades de Rodes
} 
entre hispanos, gascones, aquitanos y languedocianos siguieron siendo estrechas. Así lo prueba la participación de cruzados ultramontanos en la «Reconquista» de los siglos XI y XII, la expansión de los condes de Barcelona en Provenza (1112), la influencia del reino de Aragón-Navarra — con Alfonso I (1104-1134) - en tierras occitanas, o el vasallaje del conde de Tolosa y otros señores pirenáicos al rey Alfonso VII de León y Castilla, Imperator Hispaniae (1126-1157)5.

Este proceso se intensificó desde mediados del siglo XII al aumentar la peso político de la Corona de Aragón (1137) en la zona e intentar el reino de Castilla el control de la Gascuña Plantagenet (1204-1208)6. Los mismos tiempos

[Rodez], Albia [Albi] y Beders [Béziers], que en el tiempo de los godos pertenescien a la misma prouincia, ALFONSO X El SABIO, General Estoria (h. 1275-1289), cap. 558, ed. BRANCAFORTE, B.: Alfonso X el Sabio. Prosa bistórica, Madrid, Cátedra, 1990, p. 95. Entre los siglos V y X compartieron el gobierno de los visigodos, las invasiones musulmanas y, en Cataluña, la hegemonía del reino franco y una estructura eclesiáscica común.

3 Alfonso I el Batallador, rey de Aragón y Navarra recibió en 1108 el homenaje feudal del conde Bertran de Tolosa (1105-1109), quien le ofreció las ciudades de Rodez, Narbona, Beziers y Agde. El vizconde Bernarr Aton de Béziers racificó el acuerdo, se acogió a la protección del rey y le ofreció la ciudad de Razes. Por su parre, el conde Anfos Jordan de Tolosa (1109-1148) hizo un homenaje similar a Alfonso VII, rey de León y Cascilla, en 1134 junto a Guilhem de Montpellier y otros señores gascones y franco-occitanos, lo que llevó a decir que los dominios del Emperador hispano llegaban desde el Arlántico hasta el Ródano et facti sunt termini regni Adefonsis regis Legionis a mare magno Oceano, quod est a Patrono Sancti lacobi, usque ad fluvium Rodani-, CHRONICA ADEFONSI IMPERATORIS, ed. SÁNCHEZ BELDA, L.: Madrid, 1950, cap. 68, p. 54 (sobre la presencia del conde rolosano en la corte castellano-leonesa, véanse también los capítulos 2, 3, 4, 18, 67, 70 y 90-91). Como se encargaron de decir DÉvic, C. y Vaussète J.: (Histoire Genéral du Languedoc, reed. vol. IL, Toulouse, Privat, 1872, lib. XVI, caps. XXX-XXXI, pp. 694-697), se tracaba de una relación de dependencia nominal, pero ello no deja de probar los estrechos vínculos hispano-occitanos a los que nos referimos aquí.

6 Gracias a los éxitos diplomáticos y milizares de los dos primeros reyes de la Corona de Aragón sobre los condes de Tolosa en la llamada «Guerra de los Cien Años Meridional» (1082-11471198), "l'Etat caralan -dice BonNASSIE- est en mesure à la fin du regne d'Alfonse $I^{\text {er }}$ et au début de Pierre $I^{\text {er }}, \mathrm{d}^{\prime}$ exercer une veritable hegemonie sur $\mathrm{I}^{\prime}$ espace $\alpha c$ citan», BONNASSIE, $P$.: "Le comté de Toulouse et le comté de Barcelone du début du IX siècle au début du XII' siècle (801-1213)", *Occitania $i$ els paỉsos Catalans*. Actes $d x 8^{t}$ Colloque International de Langue et Littérature Catalane, 1217 sepsembre 1988, Univ. Toulouse-Le Mirail, Pub. de l'Abadia de Montserrat, 1989, pp. 27-45, esp. p. 44. Véase también Aureil I Cardona, M.: "L'expansion catalane en Provence au XII' sièclem, «La formació y expansió del feudalisme cataláw. Actes del colloqui organizat pel Collegi Universitari de Girona (8-11 de gener de 1985)». Estudi General, 5-6, Girona, Collegi Universitari de Girona y Universirat Autònoma de Barcelona, 1985-1986, pp. 175-195; e idem, La noce du Comte. Mariage et pouvoir en Catalogne (785-1213), París, Pub. de la Sorbonne, 1995; Bisson, Th.N., «Prelude to Power: Kingship and Constitution in the Realms of Aragon, 1175-1250m, Los mundos de Alfonso el Sabio y Jaime el Conquitsador. Razón y Fuerza en la Edad Media, ed. R.I. BURNs, Valencia, Ed. Alfons el Magnànim, 1990, pp. 49-66; y, de forma más general, CANELLAS LÓPEZ, Á.: «Relaciones políticas, militares y dinásticas entre la Corona de Aragón, Montpellier y los países de Languedoc de 1204 a 1349*, Jerónimo Zurita, 53-54 (1986), pp. 7-36; y GoNZd́lez ANTóN, L.: "La consolidación de la Corona de Aragón. 1. De Alfonso II a Jaime I», en GonZÁlez ANrón, L., Ferrer, R Y CATEURA, P.: La consolidación de la Corona de Aragón, Barcelona-Zaragoza, Editorial Aragó, 1988, pp. 
contemplaron también el flujo de peregrinos, cruzados y clérigos hacia la Península, la presencia de routiers vascos, aragoneses y navarros en las guerras del Midi - li roter $d^{\prime} E s p a n b a^{7}$ — o la habitual visita de los más famosos trovadores occitanos a las cortes de los .V. regemes d'Espanha (Peire Guilhem de Tolosa) ${ }^{8}$, síntomas todos ellos de la estrecha vinculación socio-cultural de las tierras situadas entre el Macizo Central francés y las fronteras de al-Andalus.

En cuanto a la "Epopeya Cátara»", no creo un ejercicio de "chauvinismo» sino de justicia recordar que la participación hispana fue activa e importante antes incluso de la Cruzada Albigense. Junto a otros hispanos anónimos, en ella se implicaron reyes --Pedro el Católico y Jaime I de Aragón-; reinas y condesas -Blanca de Castilla, Leonor y Sancha de Aragón-; prelados - el occitano-catalán Arnaut Amalric ${ }^{10}$, el castellano Diego de Osma o, en menor medida, el leonés Lucas de Tuy-; barones y caballeros - los catalanes Sanç de Rossellò, Guillem de Montcada, Dalmau de Creixell o el trovador Huguet de Mataplana; los aragoneses Miguel de Luesia, Gómez de Luna, Aznar Pardo o Blasco de Alagón; los navarros Hugo de Alfaro, senescal en Agenais del conde Ramon VI de Tolosa, o el jefe de roters Martín de Olite-_ ${ }^{11}$; el poeta navarro Guillermo de Tudela, autor de la primera parte de la Canso de la Crozada; y la gran figura religiosa del castellano Domingo de Guzmán. Parece más que evi-

12-99. En cuanto a Gascuña, era dote de la reina Leonor de Inglaterra, esposa de Alfonso VIII de Castilla (1154-1214). Véase una aproximación al tema en ALVIRA CABrer, M. y BURESI, P.: aAlpbonse, par la grâce de Dieu, Roi de Castille et de Tolide, Seigneur de Gascogne. Quelques remarques à propos des relations entre Castillans ec Aquitains au début du XIII ${ }^{\mathbf{e}}$ siècle», Aquitaine et Espagne an Moyen Age, Poitiers, Universicé de Poiriers (en prensa).

7 Guillermo De Tudela, Canso de la Crozada, Pref. G. Duby, Adapt. H. Gougaud, Introd. M. ZINK, París, «Letcres Gothiques», 1989, \& 94, v. 4.

B PeIRe Gullhem de Tolosa (principios del siglo XIII), Lai on cobra, ed. C. Alvar, La poesía smuadoresca en España y Portugal, Barcelona, Planeta, 1978, pp. 106-108.

9 Célebre expresión de Michel RoQuEberT, L'Epopée Cathare, 5 vols., Toulouse, Privat, 19701998; nueva reelaboración cirulada Histoire des Catbares. $L$ 'bérésie, la croisade, l'inquisition (XF -XIV siedles), Paris, Librairie Académique Perrin, 1999.

10 ...qui oriundus fuerat de Catalonia, CRÓNICA LATINA DE LOS REYES DE CASTILLA (h. 1236), ed. L. Charlo Brea, Cádiz, Universidad de Cádiz, 1984, p. 29, lín. 22. Sobre este personaje clave pata la historia occitana, véase Forrvinue, R.: «Arnaud Amaltic, Archevêque de Narbonne (1196-1225)", Gouvernement ef vie de l'Eglise at Moyen-Age. Recweil d'études, Variorum Reprints, Londres, 1979, pp. 129-146; ALvira CABRER, M.: «El venerable Arnaldo Amalarico (h.1196-1225). Idea y realidad de un cisterciense entre dos Cruzadas", Hispania Sacra, 48 (1996), pp. 569-591; KIENZIE, B.M., «Innocent III's Papacy and the crusade years, 1198-1229: Arnaud Amaury, Gui of Vaux-de-Cernay, Foulque de Toulouse», Heresis, 29 (1999), pp. 49-81; y Alvira CaBrER, M., "Le vénérable Arnaud Amaury. Image et réalité d'un cistercien entre deux croisadesw, Henesis, 32 (2000), en prensa.

1 Martín de Algai o de Olite, muerto en 1212, es llamado caballero español por PIERRE DES VAUX-De-Cernay, cronista oficial de la Cruzada (Hystoria Albigensis, ed. y trad. fr. P. GúkBin y $\mathrm{H}$. Maisonnetve, París, 1951, \& 265). Sobre el senescal Hugo de Alfaro, Ibidem, p. 128, n. 1. 
dente que sin estos personajes no es posible explicar ni comprender la historia occitano-cátara de la primera mitad del siglo XIII.

Pero icómo se vieron en la Península Ibérica los acontecimientos sucedidos entre 1209 y 1229 en tierras occitanas? 12 ¿Cuál es la «memoria historiográfica» de la Cruzada Albigense en la Espanba del siglo XIII (Corona de Aragón, Castilla y León —desde 1230-, Navarra y Portugal)? ${ }^{13}$

Antes de nada, conviene decir que la imagen de la Cruzada anticátara que nos dejaron los contemporáneos es, como ocurre con otros episodios narrados por la cronística medieval, un modelo de "manipulación» del pasado. Resulta imprescindible, por tanto, prestar tanta atención a los silencios como a los hechos que relatan las fuentes. Nuestro interés reside, pues, en observar la posición que cada autor adoptó frente a un problema sumamente comprometedor por su doble condición de conflicto religioso - la lucha contra la herejía- y conflicto político - la lucha por la hegemonía sobre las tierras occitanas- ${ }^{14}$.

Iz Un análisis similar limitado a la historiografía catalano-aragonesa y occitano-provenzal es obra de Martin AURELL. 1 CARDONA, aAutour d'un débat historiographique: 1 'expansion catalane dans les pays de langue d' oc au Moyen Âgen, eMontpellier, La Couronne d'A Aragon et les pays de Langue

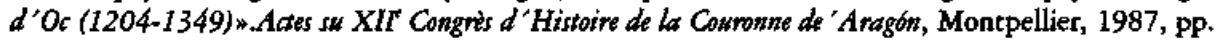
$9-41$.

13 El término Hispania-Hispaniate, Espanna, Espaigna, Espanya, Espanba, etc., denominación del conjunto del territorio y población de la Península Ibérica al margen de su división política en reinos, es frecuente -aunque no exclusiva- en los textos europeos de los siglos XI-XIII. De esta época son los conceptos. $V$. regemes d'Espanta del citado PeIrE GULLHEM DE TOLOSA o reges Hispaniae o Hispaniarum de otros trovadotes como GullLem MAGret (Aigua pueia contramon, Alvar, Paesia trovadoreca, pp. 67-68), PEIRE VIDAL (Mout es bona terr'Espanba, lbidem, p. 102) y de obras historiográficas como la CRONICA DE TOLOSA (Recueil des Historiens des Gaules et de la France, vol. XIX, Patís, 1880, p. 236), la Chronica majora (h. 125I) del inglés MATTHEW PARís (RHGF, vol. XVII, París, 1878, p. 708), la crónica del belga RAJNIER DE LIÉGE (RHGF, vol. XVIII, París, 1879, p. 623) o los ANALES DE MARGAN (Rerum Anglicarum Scriptores, t. II, Osney, 1687, p. 15). Una imagen muy descriptiva de los peninsulares en relación con otros europeos aparece en la canso eSenbor, per los nostres peccatz" (h. 1195-1212) del trovador GAVALDA, quien distingue claramente a portogals, gallicx, castellas, navars, aragones, serdas [icatalanes?], llamados espas [hispanos-españoles], de otros pueblos alamans, francer, cambrezis, engles, bretos et angevis, biams, gascos y provensals- (ed. M. DE RIQUER, Los trovadores. Historia literaria y textos, 3 vols., Barcelona, Planeta, 1975, vol. II, cap. LII, $n^{\circ}$ 208, pp. 1049-1052). Sobre este tema, véase Maravall, J.A.: «El concepto de reino y los Reinos de España en la Edad Median, Revista de Estudio Politicos, 73-L (1954), pp. 81-144 y El concepto de España en la Edad Media, Madrid, 1964; LADERo QuESADA, M.A.: «iQué es España? Imagen medieval en torno al concepto de España", Historia 16, 215 (1994), pp. 37-52; idem, «España: reinos y señoríos medievales (siglos XI al XIV)», España. Reflexiones sobre el ser de España, Madrid, RAH, 1997, pp. 95-129; GoNZÁlez ANTón, L.: España y las Españas, Madrid, Alianza Editorial, 1997, pp. 113-142; y SABATÉ, F., "La noció d'Espanya en la Catalunya medieval», Acta Histórica et Archatlogica Medievalia, 19 (1998), pp. 375-390.

14 Este esquema dual fue ampliamente desartollado por Philippe MARTEL para el conjunto de la historiografia de la Cruzada Albigense en su Tesis Doctoral inédita La Croisade des Albigeois et ses bistoriens. Nationalisme es Histoire XIX' at XX' siècles, París, 1969, tesurnida después en uLes cathares 


\section{LA HISTORIOGRAFÍ HISPÁNICA DE LA CRUZADA ALBIGENSE (S. XIII)}

\subsection{La Cruzada occitana, un problema secundario}

No todos los autores hispanos del siglo XIII se refieren al negotium Christi. El desinterés es claro en las historiografias oficiales de Portugal y Navarra, poco desarrolladas y centradas en los hechos de sus reyes, sobre todo contra los musulmanes ${ }^{15}$. Lo mismo ocurre en algunas fuentes eclesiásticas menores de Castilla y de León, ajenas a un problema lejano que no les afectaba ${ }^{16}$. Hasta en la Corona de Aragón hay obras indiferentes al tema occitano, aunque es verdad que de poco peso historiográfico ${ }^{17}$.

Entre los autores ajenos a la Cruzada Albigense hubo incluso alguno importante, como el obispo leonés Lucas de Tuy. Pese a ser testigo del desarrollo del Catarismo en el Camino de Santiago, en su obra histórica titulada Chronicon mundi (h. 1236) siguió una tradición historiográfica localista de origen altomedieval, nartando únicamente la historia de los reinos del occidente peninsular ${ }^{18}$.

et leur historiens» en DuYernoy, J., LAFONT, R, LABAL, P., MARTEL, Ph. y ROQuebert, M.: Les Cathares en Occitanie, Paris, Fayard, 1982, pp. 409-483.

15 Entre las crónicas porruguesas: BREVIS HISTORIA GOTHORUM O HISTORIA GOTHORUM (s. XIII), ed. Portugaliae Monkmenta Historica Scriptores, vol. I (Lisboa, 1856); CHRONICON LUSITANUM (s. XIII), ed. E. FlóreZ, España Sagrada, vol. XIV (Madrid, 1799), ap. xii, pp. 402419; CHRONICON CONIMBRICENSE I (281-1404), Ibidem, vol. XXIII (Madrid, 1799), pp. 329335; JOÂO DE DEO, Cbronica (h. 1227), ed. Monumenta Germaniate Historica Scriptones, vol. XXXI, (Hannover, 1903), p. 324; CRÓNICA DE CINCO REIS DE PORTUGAL, ed. A. MAGALHAES BASTO, Porto, 1945; y CRÓNICA DOS SETE PRIMEROS REIS DE PORTUGAL, ed. C. DA SIIVA TAROUCA, 3 vols., Lisboa, 1952-1954. Entre las crónicas navatras: ANALES eDE NAVARRA* (1054-1284), Biblioteca Nacional de Madrid, ms. 707; y CORÓNICAS NAVARRAS (ss. XII-XIII), ed. A. Ubieto ArTetA, "Textos Medievales», 14, Valencia, Anubar, 1964.

16 ANALES TOLEDANOS II (s. XIII), ed. FLOREZ, ES, vol. XXIII (Madtid, 1799), pp. 381423; CRÓNICAS ANÓNIMAS DE SAHAGÚN (s. XIII), ed. A. UBIETO ARTETA, «'Textos Medievales», 75, Zaragoza, Anubar, 1987; CRONICÓN BURGUENSE (h. 1212), ed. FlóREZ, ES, vol. XXIII (Madrid, 1799), pp. 310-311; CRONICÓN CERRATENSE (s. XIII), ed. A. HUICI MIRANDA, Crónicas Latinas de la Reconquista, 2 vols., Valencia, 1913, vol. I. pp. 90-94; CRONICÓN DE CARDEÑA I (h. 1327), Ibidem, pp. 373-378; y CRONICÓN DE CARDEÑA II (h. 1312), ed. FLÓREZ, ES, vol. XXIII (Madrid, 1799), pp. 378-381.

17 CRONICÓN DURTUSENSE I (Creación-1323), ed. J. VILLANUEVA, Viage literario a las iglesias de España, vol. 5 (Madrid, 1806), pp. 234-236; CHRONICON DURTUSENSE O DERTUSENTE II (ha. 1210), ed. ibidem, Fuentes, art. 1846; CRONICÓN VLINANENSE (h. 1285), ed. FLÓREZ, ES, vol. XXVIII (Madrid, 1774), pp. 334-336; y CRONICÓN VILLARENSE o LIBER REGUM (s. XIII), ed. L. SERrano SANZ, Boletin de la Real Academia de la Historia, 6 (1919), pp. 192-220 y 8 (1921), pp. 367-382.

18 LUCAs De TUY, Chronicon mundi (h.1236), ed. J. PUYOL y ALONso, Crónica de España, Madrid, Real Academia de la Historia, 1926. Fue autor de un tracado apologético contra los cátaros detectados en León y la ruta Jacobea -De altera vita fiedique controversiis adversus Albigensitum errores Libri III (h. 1230-1240), ed. J. MARIANA, Ingolscadt, 1612-. Sobre el rema, véase PÉrEZ LIAMAZARES, J.: «Los albigenses y la teología española en los albores del siglo XIII", Revista Eclesiástica, 2

Hispania, LX/3, núm. 206 (2000) 947-976 
Es, con todo, un caso especial, pues los autores hispanos más notables del momento sí trataron de una u otra forma el problema occitano-cátaro.

\subsection{La Cruzada Albigense o la necesaria lucha contra la herejía}

Frente a esta ignorancia se encuentra el relato de un poeta navarro establecido en Languedoc: Guillermo de Tudela, autor de la primera parte de la Canso de la Crozada (h. 1213) ${ }^{19}$. Se trata de una de las fuentes que más y mejor relata la fase inicial de la empresa cruzada antialbigense.

Aunque escribió en occitano y desde tierras occitanas, Guillermo de Tudela puede ser considerado bispano por su origen navarro, que él mismo reconoce, y por el sentimiento de proximidad hacia los asuntos peninsulares que se percibe en los elogios a "su rey» - Sancho VII de Navarra (1194-1234)-, en el deseo de componer otra canso para celebrar la gran victoria de los reyes hispanos sobre los almohades en la batalla de Las Navas de Tolosa (16 julio 1212$)^{20}$, y en una posición ideológica llamada «ambigua» que, sin embargo, será común a otros autores de origen hispánico: ortodoxia radical en el plano religioso; reconocimiento tácito de los derechos catalano-aragoneses-occitanos en el político ${ }^{21}$.

(1930), pp. 385-403; FERNÁNDEZ CONDE, F.J.: «Albigenses en león y Castilla a comienzos del siglo XIII", León Medieval. Once estudios, León 1978, pp. 97-114; idem, «El biógrafo contemporáneo de San Martino: Lucas de Tuy", Actas del I Congreso Internacional sobre «Santo Mantino* (1185-1985), Tuy, 1985, pp. 303-335; RoTH, N.: «Jews and Albigensians in the Middle Ages: Lucas de Tuy on heretics in Leon*, Sefarad, XII-1 (1981), pp. 71-93; PALAcros MARTín, B.: «La circulación de los cátaros por el Camino de Santiago y sus implicaciones socioculturales. Una fuente para su conocimiento", En la España Medieval, 3 (1982), 219-229; y MARTínez CaSADO, A.: «Cátaros en León. Testimonio de Lucas de Tuy», Arabivas Leoneses, 74 (1983), pp. 296-297.

19 Gunjermo de Tudela, Canso de la Crozada, pp. \&\& 1-130. Se sabe que vivió en Montauban entre 1199 y 1211 y que luego marchó a Bruniquel junto a su protector el conde Baudoin, hermano del conde Ramon VI de Tolosa. Cuando los cruzados conquistaron la villa de SaintAntonin (6 mayo 1212), Simon de Montfort se la entregó a Baudoin de Tolosa y éste concedió le concedió a Guillermo de Tudela una canongía en el capítulo de la colegiata. En 1213 desaparece su rastro. Una variante del ms. $A$ de la Canso dice de él: Era muy sabio y virtuoso, como se ba dicho en el relato, muy bien tratado por las gentes de Iglesia y por los laicos, amado y escuchado por los condes $y$ por las vizsonder [cita de MARTIN-CHABOT, E., La Chanson de la Croisade albigeoise éditée et traduite du provençal par, 3 vols., vol. I, "Les Classiques de 1'Histoire de France au Moyen Âgen, vol. 13, París, Les Belles Lettres, 1931, p. 3, n. 2).

20 Aisi conio retrair mastre Pons de Mela, / Que l'avia trames lo reis qui te Tudela / Senber de Pampaluna, del castel de la Estela / Lo melher cavalers que anc montes encela. / E sap o Miramelis qui lo paraus captela / Lo reis d'Aragó i fo, e lo reis de Castela; / Tuit essems i feuro de Lor trencant lamda, / Qu' en ne cug encar far bona cansó novela / Tot en bel pergamin, GUILERMO DE TUDELA, Canso de la Crozada, \& 5, w. 16-24. Otras referencias de interés en \&\& 1,7,33, 37 y 93-94.

2i Lo reis Peyr d'Arago una seror doná / Al comte de Tolosa, e puis s'en marida / Un'autra a so filh, malgrats d'aquels de sa. / Ers'es mes en la guerra e si ditz que vindra / Ab be mil cavaliers, que totz pagatz les $a ;$ / E si los crozatz troba, ab lor se combatra. / $E$ nos si tant vivem veirem cals vencera, / $E$ metrem en esto- 
En todo caso, Guillermo de Tudela fue el único autor peninsular que dedicó su relato por entero a la Cruzada. Todos los demás adoptaron el «événementialisme» propio de la historiografía medieval, reduciendo un complejo proceso a dos o tres episodios que impactaron a los contemporáneos ${ }^{22}$.

Así, la génesis y primera fase de la Cruzada (1209-1213) quedaron resumidas en la gran campaña de 1209 contra las ciudades de Béziers y Carcassonne. Son pocas, con todo, las fuentes que hablan de estos sucesos. Lo hacen una fuente catalano-aragonesa menor como la Crónica de Roda (h. 1209) ${ }^{23}$ y, sobre todo, dos importantes crónicas eclesiásticas castellanas. La más antigua es la Crónica Latina de los Reyes de Castilla (h. 1236), obra de un obispo anónimo muy bien informado sobre la Europa de la época ${ }^{24}$. Similar es la versión de la Histo-

ria so que nos membrara, / E escrixrem encara so que nor sovindra, / Aintant cant la materia ad enant durara / Tro la guerra er finea, \& 130. ¿No podríamos ver aquí la simpatía hacia una usolución catalanoaragonesa» del conflicto que setía esa «troisième voie salvatrice» sugerida por Colette BortinFOURCHOTTE como posible causa de la sambigüedad» de GuILIERMO DE TUDELA? Eliza M. GHIL afirma que el trovador navarro defendía la reconciliación de nobles franceses y occitanos en forma de una «alianza clerical-caballeresca» destinada a combatir al enemigo común que eran los herejes ( $L$ 'Age de Parage. Essai sur le poétique et La potitique en Occitanie au XIII' siècle, "University Studies in Medieval and Renaissance Literatures, 4, Nueva York-Berna-Frankfurt am Main-París, Peter Lang, 1989, esp. pp. 91-149). En todo caso, esta postura eoficial" -en expresión de Michel ZINK (Canso, p. 23)- no descartaría que tal alianza se formara bajo la égida feudal del rey de Aragón, algo que en 1213 admitiría el propio papa Inocencio III. Las palabras de GUILLERMO DE TUDELA reconociendo el derecho de Pedro el Católico a intervenir militarmente en la zona y esperando, sin emitir juicio alguno, a la resolución armada del conflicro recogen abiertamente el discurso oficial catalanoaragonés y se alejan de la "solución franco-eclesiástica" -la defendida por VAUX-DE-CERNAY-que acabarían imponiendo los partidarios más radicales de la Cruzada en el IV Concilio de Letrán (1215). Sobre esta cuestión véase también GuIBAL, G.: Le Poëme de la Croisade contre les Albigeois ou l'épopée nationale de la France dn Sud an XIlle siedle. Étude bistorique et litteraire, Toulouse, Impr. A. Chauvin, 1863; MEYER, P.: «Recherches sur les auteurs de la Chanson de la Croisade Albigeoises, Bibliothéque de l'École des Cbartes, 1 (1865), pp. $401-422$ (reed. Nueva York-Londres, Jonhson Reprint Corporation, 1965); Higounet, Ch.: «A propos de Guillaume de Tudèle», Annales du Midi, 50 (1938), pp. 377-379; MARTin-Chabot (ed.), La Chanson, vol. I, París, 1960, Introducción; Delaruélue, E.: «L'idée de Croisade dans la Cbanson de Guillaume de Tudèle», Annales de l'Institut d'Etudis Occitans, «Actes du Colloque de Toulouse» (sept. 1962), pp. 173-187; DossAT, Y.: «La Croisade vue par les Chroniqueurs", Cabiers de Fanjeaux, 4 (1969), pp. 221-259; LejeUNE, R: "L'ésprit de la Croisade dans I'épopée occitane», Ibidem, pp. 143-173; Bơtrin-FouRCHOTTE, C.: "L'ambigüiré du discours chez Guithem de Tudèla», Annales de la Faculté des Lettres et Sciences bumaines de Nice, 29 (1977), pp. 99-110, esp. p. 109); y MARTEL, «Les Cathares et leurs hiscoriens», pp. $412-418$.

22 La expresión es de AUREI, "Autour d'un débat historiographique», pp. 10-15.

23 NECROLOGIO DE RODA o CHRONICON ROTENSE (h. 1209), ed. FLÓREZ, ES, vol. XIVI, pp. 339-345.

${ }_{24}$ El autor podría ser Juan de Osma, canciller del rey Fernando IL de Castilla y León (12171252) según Lomux, D.W.: "The autorship of the Cbronique Latine des Rois de Caxtille», Bulletin of Hispanic Studies, 40 (1963), pp. 205-211; y CHARLo BREA, L.: (ed. y trad.), Crónica Latina de los Reyes de Castilla, Madrid, Akal, 1999, pp. 13-18. El texto dice: Papa siquidem Romanus Innocencius 
ria de rebus Hispaniae (1243-1247) del arzobispo de Toledo Rodrigo Jiménez de Rada (h. 1170-1247), hombre culto, políglota, formado en Paris y Bolonia, con una posición religioso-política de máximo nivel en la Iglesia hispana, numerosos contactos internacionales y gran prestigio en Roma ${ }^{25}$.

La posición de estos dos prelados frente a la «Cruzada Relámpago» ${ }^{26}$ de 1209 es idéntica a la de otros eclesiásticos favorables a la eliminación violenta de los herejes. Estamos, pues, ante la postura de la Iglesia castellana —podría decirse hispana- respecto al Catarismo: era un mal que debía erradicarse mediante una guerra justa y santa.

Ambos relatos revelan, al tiempo, que la posición de la Iglesia hispana sobre la Cruzada Albigense no fue homogénea. La Crónica Latina reproduce las expresiones e ideología de los partidarios más duros de la Cruzada -el "partido franco-eclesiástico" cuyo portavoz era el cisterciense Pierre des Vaux-deCernay ${ }^{27} \rightarrow$, una visión maniquea de la lucha entre el Bien (los cruzados) y el

tenius dederat remissionem generalem peccatorum omnibus illis qui uenirent super Albigenses et alios bereticas qui erant in partibus illis. Pululauerant nanque bereses diuterse, facies quidem babentes diuersas et caudas colligatas, et multiplicabantur cotidie adeo quad periculosum erat uniuersali eclesie amplius talia dissimulare. Catholici engo de diwersis partibus et precipue de regno Francie uenientes, fere totam terram illam in modico tempore Christi fidei subiugauerunt, castra multa ef cinitates munitissimas, quasi inexpugnabiles, in momento temporis subuertentes, bereticos ipsos diversis penis affligentes et uariis mortibus interimentes, CRÓNICA LATINA, p. 39, lín. 9-21.

25 Fue organizador y cronista de la Cruzada de Las Navas de Tolosa (1212), protagonista en el IV Concilio de Letrán (1215), legado en España (1217-1218), Canciller Mayor del Reino, impulsor de las universidades de Palencia y Salamanca e iniciador de las obras de la Catedral de Toledo. Su relato forma parte del relato de Las Navas: Advenit etiam uenerabilis Amaldus, qui aliquandi sollicitudine Cistercii functus tunc regebat ecclesiam Narbonensem. Hic pauco ante emulatione legis catbolice prouocatus contra quosdam, qui in Narbonense et uicinis prouinciis blasphemare nomen Domini et Ecclesiam ore nepbario presumpserunt, corda fidelium excitauit ut signo crucis contra bereticorum uersucias armarentur. Et sic factum set per Dei gracian, quad ubi contempta predicatio non profecit, falce crucis putatis beresibus fides catholica de die in diem feliciter coalescit; et destructis Biterris et Carcasona blappbemancium sanguis flama worace et ulsrici gladio ast consumptus era MCCXLVI, RODHGO JIMÉNEZ DE RADA, Historia de Rebus Hispaniae sive Historia Gothica, ed. J. Fernández Valverde, «Corpus Christianorum, Continuatio Medievalis», LXXII), Turnhout, Brepols, 1987, lib. VIII, cap. ii ( $($ De adventv vistanontanorm ad bellim**), p. 260, lín. 5-16. Sobre el personaje, véase también GorosterruTzU, J.: Don Radrigo Jiménez de Rada, gran ertadista, escritor y prelado, Pamplona, 1925; BALLESTEROs GAIBROIs, M.: Don Radrigo Jiménez de Rada, Barcelona, Labor, 1943; Grassotrr, H.: «Don Rodrigo Ximenez de Rada, gran señor y hombre de negocios en la Castilla del siglo XIIH", Cuadernos de Historia de España, 55-56 (1972), pp. 1-302.

26 LABAL, P., Los cátaros. Hergiza y crisis sacial, Barcelona, Crítica, 1984, pp. 155-158.

27 Su ya citada Hystoria Albigensis (1218) fue la crónica uoficial" de la Cruzada e inspiración de buena parte de las crónicas y anales de la Europa del siglo XIII sobre escos hechos. En el reino de Francia: GuILlaume Le BreTon, Gesta Philippi Akgusti, francorum Regis (h. 1220), RHGF, vol. XVII (París, 1878), pp. 62-116.; y Philippidas Libri XII sive “Gesta Pbilippi Augasti, Francorum Regisv versibus beroicis descripta (h. 1226), ed. latina en verso lbidem, pp. 219-225 y ed. fr. en prosa F. Guizot, "Collection des Memoires relatifs à l'Histoire de Francen, París, 1825, vol. 12; CRÓNICA DE ARDRES (h. 1234), RHGF, vol. XVIII (París, 1879), pp. 568-583; CRÓNICA DE MONT-SAINTMICHEL. CONTINUACION ANONIMA (1211-1239), RHGF, vol. XVIII (París, 1879), Pp. 333- 
Mal (los occitanos) con un conde de Montfort, jefe del ejército de Dios, idealizado como modelo de miles Christi ${ }^{28}$. Esta perspectiva tan «cisterciense» no existe en el Toledano pese a su ardiente justificación de la terrible campaña de $1209^{29}$.

Para entender esta doble visión hay que acudir al episodio de la Cruzada que causó mayor conmoción en la Europa de la época: la derrota y muerte del rey Pedro el Católico de Aragón a manos de los cruzados de Simon de Montfort en la batalla de Muret (12 septiembre 1213) ${ }^{30}$. Este suceso no sólo fue recogido por todos los cronistas peninsulares - y europeos- del negotium, sino que en la mayoría llegó a monopolizar el recuerdo de la cuestión albigense. En realidad - y de aquí su importancia-, el recuerdo de la batalla de Muret se convirtió para casi todos los autores hispanos del siglo XIII en la única memoria de la Cruzada contra el Catarismo.

348; AUBRY DE TROIS-FONTAINES, Cbronica (h. 1241), MGHSS, vol. XXIII (Hannover, 1874), PP. 674-950; VINCENT DE BEAUVAls, Speculum bistoriale (h. 1254), «Bibliotheca mundi Sev. Speculin, 6 vols., Doaci, 1624, vol. 6, lib. 30; BAUDOUIN D'Avesnes, Chronica (h. 1270), ed. HGL, vol. VII (Toulouse, 1879), Nota 17, pp. 52-54; Guillaume De PUYlaurens, Chronica (h. 1273), ed. J. DUVERnOY, «Classiques de I'Histoire de France au Moyen Âge», París, CNRS, 1976; CRÓNICAS DE SAINT-DENIS (s. XIII), RHGF, vol. XVII (París, 1878), pp. 403 y ss.; GULLAUME DE NANGIS, Chronica (h. 1300), Ibidem, vol. XX (París, 1840), pp. 544-586 y 725-763; BERNARD GUI, Praeclara Francorum facinora, ed. F. Gulzot, Gestes Glorieux des Franģais, «Collection des Mémoires relarifs à l'Hisroite de France», vol. 15, Paris, 1824. En Inglaterra, ANALES DE ROGER OF HOVEDEN-CONTINUACIÓN ANÓNIMA (1202-1223), RHGF, vol. XVIII (París, 1879), pp. 164-168; ANALES DE WAVERLEY (1-1291), Ibidem, pp. 188-210; RaLPH OF COGGESHALE, Cbronico anglicano (h. 1224), Ibidem, pp. 59-120; MATTHEw PARIS, Cbronica majora, Ibidem, vol. XVII (París, 1878), pp. 680-768; ANALES DEL PRIORATO DE DUNSTAN (h. 1242), Monastic Annals, Rerum britannicartum medii aevi scriptores, Rolls Series, Londres, Longmans and Co., 18581896, 244 vols., vol. II. En Iralia, la CRÓNICA DE FAENZA (h. 1226-1236), ed. L.A. MURATOR!, Rerum Italicarum Scriptores, vol. XXVIII-1 (Bolonia, 1936), esp. pp. 125-126.

28 Operabatur siquidem manifeste et miraculose sirtus Domini nostri lesu Cbristi, qui est rex regum et dominus dominancium, per ministeriwm illustrissimi et fidelissimi comitis Simonis Montis Fortis, qui velsd alter ludas Macabeus, legem Dei zelans, wiriliter et potenter bella Domini preliabatur, CRÓNICA LATINA, p. 40, lín, 5-10. Esta identificación de Simon de Montfort con alter Iudas Marabeus se repite en otras fuentes como las normandas CRÓNICA DE MORTEMER-EN-LYONS (1113-1235) y CRÓNICA $D E$ ROUEN (1-1338): $A$ diebus Judae Machabaei usque in praesentem diem, tantam multitudinem tam mirabilem à paucissimis tam mirabiliter victam, catsam atque fugatam, nunquam et nusquam legimus (RHGF, vol, XVIII, Paris, 1879, pp. 355 y 360).

29 Se trata de una visión muy acorde con el "paranoicon temor al fantasma de la herejía recreado por el «imaginario cisterciense» durante el siglo XII, BIGET, J.L.: «Les Albigeois, remarques sur une dénomination", ZERNER, M. (dir): Inventer l'bérésie? Discours polemiques et pouvoirs avant l'Inquisition, Niza, "Collection du Centre d'Études Médiévales de Nice", 1998, pp. 219-255.

${ }^{30}$ El trabajo más serio sobre este acontecimiento sigue siendo el volumen II de $L$ 'Épopéé Cathare de Michel RoQueberT, titulado 1213-1216, Muret ou la dépossession, Toulouse, Privat, 1977. Un análisis -del que forma buena parte este trabajo- desde las perspectivas histórico-militar, ideológica, mencal e historiográfica puede verse en ALVIRA CABRER, M.: Guerra e Ideologia en la España Medieval: Cultura y Actisuder Históricas ante el giro de principios del siglo XIII-Batallas de Las Navas de Tolosa (1212) y Muret (1213)-, Tesis Doctoral inédita, Madrid, Universidad Complutense, mayo 2000, II Parte. 


\section{CruZada albigense y muerte del Rey de Aragón: El recuerdo de MURET}

Desde septiembre de 1213, los cronistas de toda Europa debieron explicar cómo un prestigioso rey cruzado había muerto combatiendo contra el ejército de la Iglesia junto a unos vasallos acusados de herejía. Se plantearon diferentes soluciones, ninguna exclusivamente hispana, pero puede decirse que el examen de las fuentes peninsulares revela una cierta posición mayoritaria sobre este grave acontecimiento.

\subsection{El justo castigo divino: la victoria del Ejército de Dios}

El relato más original es el de la Crónica Latina de los Reyes de Castilla. Su autor cita las relaciones político-familiares del rey de Aragón y del conde de Tolosa, pero no para justificar un enfrentamiento con la Cruzada que creyó en sí mismo pecaminoso. Muret fue, para él, el justo Juicio de Dios a un rey que había ayudado a los cómplices de los herejes ${ }^{31}$. En la Iglesia hispana - sobre todo en Castilla y León- hubo, pues, una corriente de opinión favorable a la Cruzada Albigense y con una percepción "exclusivamente religiosa" del problema cátaro muy similar a la del clero más intolerante con los enemigos de Dios. Sin el radicalismo de autores cistercienses mucho más extremistas, esta corriente consideró que las tazones «laicas» del rey de Aragón, aunque ciertas, no podían perturbar la imperativa eliminación de la herejía ${ }^{32}$.

31 El autor lamentó así su muerte: Felix fuisset rex ille, si uitam finisset statim post nobile triumphum belli commissi in Nauas de Tolosa contra regem Marroquitanum, CRÓNICA LATINA, pp. 39-40. Sobre la batalla campal como Juicio de Dios en esta época, véase DuBY, G.: Le dimancbe de Boutuines, «Colleccion Trente Journées qu' on fait la France», N.R.F., París, Gallimard, 1973; reed. Sarthe, 1985; trad. española El domingo de Bozvines, Madrid, Alianza, 1988; y Alvira CABRER, M.: «Dimensiones religiosas y liturgia de la batalla plenomedieval: Las Navas de Tolosa, 16 de julio de 1212", XX Siglos, 19 (1994), pp. 33-46; y, sobre todo, Guetra e Ideologia...

32La CRÓNICA LATINA se sitúa a medio camino entre los «cruzadistas" más radicales y los «moderados» que mostraton gran simpatía hacia Pedro de Aragón y reconocieron las razones político-familiares que le llevaron al enfrentamiento con la Cruzada, Entre los primeros destacan los Anales de la abadía inglesa de Waverley (1-1291): Rex Arragoniae, diabolico instinctu deceptus, collecto exercitu copioso, nefandus etiam Comes Sancti Egidii rum omni exercitu suo, et alii quam plures ex illis Provinciis infideles, praeliwm inierunt contra Simonem de Monteforti, et obtinuerunt civitates et castella quatdam quate ipse Simon prìus super baereticos adquisierat. Unde Simon, super boc nimis consternatus, et in paucitate virorum suorum respectu multitudinis adversariorum pawore perterritus, confidens tamen in misericordia omnipotentis, suos confortans ne formidarent ad adventum Vascionum, sed in mente baberent adjutoria sibi facta de coelo, et non desperarent ad omnipotente affuturam sibi victoriam; admonens etiam, ad memoriam certamina quate anno praecedenti fecerant, retocare, istis et multis verbis animos eorum corroboravit, ut cum fervore caritatis inceptum negotium peragerent. Haec ipso proferente, nunciatus est ei adventus Jobannis de Bares, militis nobilis, quem Rex Franciae cum aviss pluribus misit in auxilium: unde Simon gavisus est, es bi qui cum ipso erant. Rex vero Arragoniate, in multitudine peditum et equitum confidens, ad bellum properabat: cui in obviam venit 
En todo caso, esta posición maniquea, sobre todo en sus formas y expresiones, fue excepcional en la cronística hispánica del siglo XIII. Todos compartían la misma ortodoxia católica, pero pocos antepusieton el criterio puramente religioso a unas circunstancias político-morales que les afectaban directa e incluso, en ocasiones, personalmente ${ }^{33}$ El trágico e incómodo episodio de la batalla de Muret sería objeto, por ello, de muy diferentes aproximaciones e interpretaciones.

\title{
3.2. Los silencios de Muret
}

Frente a esta difícil papeleta, algunos autores adoptaron la solución más sencilla: no decir nada, salvo la muerte del rey Pedro.

Sucede en algunos anales y cronicones de Cataluña y Castilla ${ }^{34}$. Son, por tanto, una tipología de fuentes normalmente breves, pero no hay por qué descartar un deliberado ocultamiento de las circunstancias de la batalla de $\mathrm{Mu}$ -

\begin{abstract}
Simon virtute Dei magni, quâ roboratus, firmiter suis praecipiendo dixit: «lctibus a prima fronte pugnae pugnare nolite contra inimicos; sed fortiter, ut cbristiani milites, acies superborum penetrare securix. Accedentes ergo ad certamen omnes uno impetu, et imperatum fuit, nuda peditum deservere praesidia, et usque ad Regem penetraserunt; sicque demam contritus et exercitus regis, et undique gladio caesws. Ipse quidem Rex per manum Jobannis captus est, qui per visum eum cognoverat, quam vis regalia arma, quae priús babuerat, deposwerit, alia asswmens. Quidam vero ex comitatu qui de pradictione milites vocabantur, illum in frustra consciderunt, dicentes non debere apostatam vivum ducere, sed statim interfici; quo interfecto, exencitus omnis dispersus est, multis simul interfectis absque numero. Ipse etia Comes Sancti-Egidii, de praelio vix evadens cum paucis, cum quó se verteres prate confusione nesciret, in Angliam ad nepotem susm Jobannem Regem venin deliberavit, et fecit sic; sed inde non multo post per Nicolaum legatum domini Papae aliosque fideles, tamquam Sanctae Ecolesia inimicus, expulsus est. Fuit autem istud bellum infra octavas Nativitatis Beatae Mariae... (RHGF, vol. XVIII, pp. 202-203).

Entre los segundos hay fuentes francesas como la $C R O N I C A D E L A O N$ (h. 1219), RHGF, vol. XVIII París, 1879, p. 716; la Cbronologia (h. 1227) de ROBERT D'AUXERRE, lbidem, p. 282; y la Cbronica (h. 1241) del cisterciense AUBRY DE TROIS-FONTAINES: De rege Petro Arrogonum dicitur, quad won sine dolore utriusque exercitus occubuit, quia multa prelia egerat in fide catbolica. Et quia Tolosanus duscerat unam eitus sororem (Leonor) et filius eizs altera (Sancha\}, id circo in illorum parte inventus est, quia qui tetigerit picen inquinabitur ab ea... (MGHSS, vol. XXIII, Hannover, 1874, p. 897).

33 Es curioso que la CRÓNICA LATINA sea la fuente peninsular que más informa sobre los asuntos internacionales del primer tercio del siglo XIII. Su posición resulta así muy reuropea» en contraste con la perspectiva historiográfica e ideológica «hispánica» o peninsular de sus contemporáneos.

34 En la Corona de Aragón, el CRONICON BARCINONENSE I (985-1311) y II (1136-1308), ed. FLókEZ, ES, vol. XXVIII (Madrid, 1774), p. 332; y el CRONICÓN ULINANENSE (h. 1285): Anno MCCXII. interfectus fuit Dominus Petrus Rex Aragonum apud Morellum XVII. Kal. Octobris (ed. PIERRE De MARCA, Marca Hispanica, París, 1688, col. 759); En Castilla-León: el CRONICóN COMPLUTENSE (h. 1226), ed. HUICI, Cónicas Latinat, vol. I, p. 76; los ANALES TOLEDANOS III (h. 1244), Ibidem, vol. I, p. 363; y los ANALES COMPOSTELANOS (0-1248): Petrus Rex Aragoniae fuit inserfectus à Gallis apud castrum quod dicisur Munet. II Idus Septembris Era MCCLI (ed. FlóREZ, ES, XXIII, Madrid, 1799, p. 324).
\end{abstract}

Hispasia, LX/3, núm. 206 (2000) 947-976 
ret $^{35}$. Esto explicaría su similitud con noticias procedentes de ámbitos igualmente favorables a la Corona de Aragón u hostiles a los franceses, como el occitano o el anglo-Plantagenet ${ }^{36}$.

Estos autores eran fieles a la Iglesia, pero afines a la figura política y/o personal de Pedro el Católico: para catalano-aragoneses y occitanos era su rey y señor; para castellanos, tolosanos y angevinos era un amigo, un aliado o un pariente de su propio rey. No podían olvidar la memoria del monarca muerto, pero tampoco mancharla como querían sus enemigos. Era mejor guardar silencio $^{37}$.

Entre estas discretas fuentes sobresale el sentido testimonio de los Anales o Crónica de San Víctor de Marsella (715-ha. 1563), abadía de la Provenza catalano-aragonesa muy ligada a la iglesia de Cataluña:

Noscant presentes et futuri, quod anno dominice incarnationis MCCXIII Petrus illustris Rex Aragonensis apud Tolossam in bello quod habuit cum Francigenis, peccatis exigentibus, interfectus fuit: de cujus morte tota christianitas lugere debet et tristari3 3 .

Las palabras del único cronista provenzal de la Cruzada muestran la contradicción extrema entre ortodoxia religiosa e intereses políticos que culminó en 1213. La postura eclesiástica «oficial» no empaña el dolor por el soberano caído. *Comment le scribe monastique pourrait-il donc assumer les contradic-

35 La concreción intrínseca de estas obras no impidió que acontecimientos notables de la época fueran tratados con más detalle por sus autores: es el caso de la batalla de Las Navas de Tolosa en los ANALES TOLEDANOS I (ed. FlórEZ, ES, vol. XXIII, Madrid, 1799, pp. 395-399), los ANALES COMPOSTELANOS, (Ibidem, p. 324), el CRONICON COMPLUTENSE (Ibidem, p. 316) e incluso la CRÓNICA DE SAN VICTOR DE MARSELLA (RHGF, vol. XIX, París, 1880, p. 238).

36 Como la CRÓNICA DE SANT SERNIN DE TOLOSA (1096-1230): MCCXII, Rex Aragonum cum exercitu suo et populo Tolosano, mortuns at in obsidione Murelli... (DÉvIC, C. y VAISSÈTE, J.: Histoire Genéral du Languedoc, reed. vol. V, Toulouse, 1875, col. 51); la CRÓNICA EN LANGUEDOCIANO DEL CONDE RAMON VII DE TOLOSA (h. 1249), RHGF, vol. XIX (París, 1880), p. 235; la CRÓNICA DE MONTPELLIER (s. XIII), citada por J. MIRET I SANS, «Itinerario del rey Pedro I de Cacaluña, II en Aragón (1196-1213)», Boletint de la Real Academia de Buenas Letras de Barcelona, 4 (1907-1908), p. 105; o la CRÓNICA DE SAINTE-COLOMBE DE BORDEAUX (s. XIII), $R H G F$, vol. XVIII (París, 1879), p. 245.

37 Este silencio consciente sobre Muret fue adoptado por autores tardíos de la Corona de Aragón como Ramon MUNTANer (Crònica, h. 1328, ed. F. SOLdevila, Les Quatre Grans Cròniques, Barcelona, 1971, pp. 667-1000), JOAN FrancESC (Libre de les nobleses dels reys, h. 1350-1400, Biblioteca de Catalunya, ms. 487) o GABRIEI. TURELI. (Recort bistorial de algunas antiquitats de Catalunya $y$ Franta, 1476, ed. J. CASAS-CARBÒ y J. MASSÓ TORRENTS, Barcelona, Imprempta i Llibreria de "L. Avenç", 1894).

38 ANNALES SANCTI-VICTORI MASSILIENSIS, RHGF, vol. XIX (París, 1880), p. 238. Véase también DEvos, J.-C., «L'extention de la congrégation de Saint-Victor en Espagne», Bulletin philologique et Historique, 1969, pp. 349-358; y AMARGIER, P.A., «Rapports de la Catalogne ec des vallées du Labéda avec Saint-Victor de Marseille», ibidem, pp. 359-371.

Hispania, LX/3, núm. $206\{2000\} 947-976$ 
tions d'un tel personnage?», se pregunta Aurell ${ }^{39}$. En realidad, la contradicción no estaba tanto en el rey Pedro como en el sinsentido al que condujo la "guerra santa en país cristiano» iniciada por Roma en $1209^{40}$. Desde el scriptorium de su abadía, el monje marsellés no se atrevió a exculpar al rey de Aragón; desde una perspectiva menos mediatizada, otros no tardarían en intentarlo.

\subsection{Las explicaciones del desastre}

Es cierto que esta posible ignorancia consciente se vio acompañada por el shock derivado de la inesperada muerte del rey de Aragón ${ }^{41}$. Pero ante la complicidad de Pedro de Aragón con los herejes explotada por los partidarios de la Cruzada, los autores más próximos al rey muerto pronto advirtieron que el silencio no era suficiente. Aparecieron entonces diferentes versiones de la batalla de Muret.

a) La primera «versión oficial»: los Gesta Comitum Barcinonensium I y la «solidaridad hispánica» con el rey Pedro (1214-1221)

Lógicamente, fue en la Corona de Aragón, la más afectada por lo sucedido en 1213 , donde surgió el primer relato «oficial» de la derrota de Muret. Fue obra de los monjes de Ripoll en los primeros Gesta Comitum Barinonensium et Reges Aragonensium (1214-1221), historia oficial de los condes barceloneses -luego reyes de Aragón- desde el siglo X. Se trata de la misma explicación «exclusivamente políica» de la intervención militar de Pedro el Católico repetida en fuentes occitanas: silencio sobre la herejía, abusos injustos de los cruzados y defensa del conde de Tolosa frente a la ambición desmedida de Simon de Montfort ${ }^{42}$. Esto

\footnotetext{
39 AuRELI, "Aurour d'un débar historiographique», pp. 11-12.

4o Expresión de PISsARD, H.: La guerre sainte en pays cbrétien. Essai sur l'origine et les developpements des tbéories canoniques, «Bibliothèque d'Histoire Religieuse», 10, París, 1912.

41 «Sorte de scandale absolu, et son désespoir rétrospectif paraît avoir occulté en lui la plus élémentaire cutiositén, ROQUEBERT, L'Épopée Cathare, vol. II, p. 232.

42 GESTA COMITUM BARCINONENSIUM ET REGES ARAGONENSIUM 1 : ...andient comitem Montisfortis in exberedationem sororum suarum intendere, equanimiter non potuit sustinere, at multis precibus sine admonitionibus premissis, multis etiam super boc domino pape nuntiis transmissis, animum comitis Montisfortis a sali proposito nunquam potuit resacare. Hac de causa in iram excitatus, exercitus suos contra ipsum comitem Montisfortis direxit... (ed. L. BaRRAhU-DIHIGo y J. Massó TORRENTS, Barcelona, 1925, vol. II, cap. X, pp. 17-18). La repiten GUILIERMO DE TUDELA (\& 130), el continuador de la CANSO DE LA CROZADA (2\& 131-132) y una Vida de RAIMON DE MIRAVAl (h. 1191-1229), trovador ligado a la Casa de Tolosa, compuesta probablemente por el trovador UC DE SANT-CIRC (h. 1211-1253): Quans lo coms de Toloza fo dezeretatz per la Gleiza e per los franses, es ac perduda Argensa $a$ Belcaire, el frances agron Saint Gili et Albuges e Carcases, $e$ Bederres fon destruitz, e. l vescoms de Bezers era mortz, e tota la bona gens $d$ 'aquelas encontradas foron morta e fugida a Toloza $[\ldots]$ Et avene se que $l$ reis d'Arago venc a Toloza, per parlar al comte e per vezer sas serors, ma dona Elionor e ma dona Sancha; e si

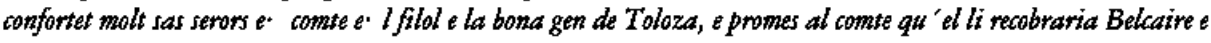


es, la Cruzada Albigense reducida a una disputa feudal provocada por un vasallo rebelde: sin herejía no había complicidad del monarca, ni Juicio de Dios en la explicación de la derrota ${ }^{43}$.

Lo relevante de esta versión oficial es que apareciera más allá de la Corona de Aragón y el país occitano ${ }^{44}$. En la Península, aparece abreviada hacia las mismas fechas en dos fuentes de Castilla: los Anales Toledanos $I$ (h. 1219) y, más sutilmente, la obra Planeta (1218) de Diego García de Campos, canciller de los reyes Alfonso VIII y Enrique I entre 1192 y 1217 . Éste último condenó duramente la herejía recordando sin complejos las reivindicaciones de los catalanes al norte de los Pirineos ${ }^{45}$.

Esta asimilación del esquema «oficial» de los derrotados de Muret puede explicarse por la solidaridad con un monarca amigo, aliado y pariente de los reyes castellanos. Pero aquí podríamos ver también un sentimiento de «solidaridad hispánica» que hizo frente al descrédito de Pedro el Católico acogiendo durante décadas - y con mayor empeño y claridad que en el resto de Europa- las versiones más favorables al monarca muerto en 1213. Sólo así se explica que esta interpretación fuera repetida sin cambio alguno a mediados de

Carcasona, et a* N Miraval lo sieu castel; e que faria si que la bona gens cobrarion lo joi c'avion perdut [...] Per que - I reis venc ab mil cavaliers a servizi del comte de Toloza, per la promessio qu'el avia faita de recobrar la terra que l coms avia perduda. Don lo reis fo mortz per lo franses denan Murel, ab totz los mil cavaliers c'avia ab se; que nuils non escapet (ed. RIQUER, Los trovadores, vol. II, cap. XLIX, n' 197, pp. 995-997; también GHIL, $L$ 'Age de Parage, pp. 23-24 y 38 y ss.; y GUIDA, S.: «Uc de Saint Circ et la Crociaca contro gli Albigesin, Cultura Neolatina, 57 (1997), pp. 19-54)

${ }^{43}$ Ésta se debió a causas militares y caballerescas: in bello campali ab ipso comite size a crucitis stis deficientibus interfectus est, et maluit mori in bello quam si witus exiret de campo.

${ }_{44}$ Resumida llegó a fuentes eclesiásticas francesas moderadas como la CRÓNICA DE LAON (h. 1219), AUBRY De Trois-FonTAines (h. 1241) y ROBERT D' AUXERRE (h. 1227) en cuya Chronologia dice así: ...Tholosani bereticis, babentes secum Petrum regem Arragonum, qui venerat in adiutorium sororii swi, scilicet comitis Tholosani. Ditplicuit tgitur Domino via eitus, eo quod bereticis puberet auxilium et earum protectori amicicia umgeretur. Unde cum in itso conflictu bellico multi bereticorum accumberent, et ipse accubuit inter multos... (RHGF, vol. XVIII, Patís, 1879, p. 282). Estas versiones explican -no justifican- la presencia del rey de Aragón en Muret, pues sus autores mantuvieron un esquema intexpretativo "religioso» favorable a la Cruzada. En este sentido, su perspectiva sólo es equiparable en la Península a la de la CRONICA LATINA. Con todo, prueban el gran prestigio de Pedro el Católico en círculos ortodoxos incluso después de 1213.

45 ANALES TOLEDANOS I: Fue el Rey de Aragon con sur Ricos omes ayudar al Conde de Tolosa, è lidió con el Conde de Montfuert, é mataron y al Rey Daragon en el mes de September, Era MCCLI (ed. FLÓ. REZ, ES, vol. XXIII, Madrid, 1799, p. 399). DIEGo GARCiA DE CAMPOS lo hace en una carta dirigida al arzobispo Rodrigo de Toledo lamentando el estado de la Europa de su tiempo; sobre la muerte del rey Pedro dice: Quando aragonensis debilior conpore quam etate. opsare debet ut regnum forcius possit regere quam personam [Jaime I] Quando Catbalonia in ipsis singulibus letabunda: occisum a gallis dominum [en Murec] sepe verbis vindicat. nunquam factis Quando Narbona Labilis. inter ducem et archiepiscopum lubricata: utrique debita. neutri subdita. utrique suspecta. neutri despecta. ambobus superba. inter manus senencium anguillatur. Quando misera nec miseranda Provincia miserabiliter arriana contra ecclesiam minus recalcitrat quam rebellat (ed. M. ALONSO, Madrid, CSIC, 1943, p.196). 
siglo en fuentes no catalano-aragonesas como el navarro Libro de las Generaciones (h. 1260) ${ }^{46}$.

b) La «versión oficial autorizada»: el arzobispo Rodrigo de Toledo y la exculpación del rey Católico (1243-1247)

Esta hipótesis también daría sentido a un hecho singular: la versión de Muret que más claramente exculpa a Pedro de Aragón no es catalana, ni aragonesa, sino castellana. Su autor es el arzobispo Rodrigo de Toledo en su De rebus Hispaniae, visión unitarista de la historia de Hispania en torno al eje vertebrador de los reyes de Castilla-León como herederos de la antigua monarquía visigoda. El penúltimo capítulo dedicado a la Corona de Aragón -De Petro rege Aragoniae et eivs morte - narra con conocimiento la batalla de Muret. Cita, como los Gesta I, el vínculo familiar Aragón-Tolosa en el origen del choque, argumento clave de los dertotados, pero no a Simon de Montfort ni su vasallaje hacia el rey, explicando la derrota por causas militares - huida de los condes occitanos y de los catalanes-. A todo ello sigue un comentario muy significativo:

Nec rex Petrus, cum esset plene catholicus, in fauorem uenerat blasphemorum, set, ut diximus, affinitatis debito prouocatus ${ }^{47}$.

Hay que decir que esta misma explicación aparece en una fuente francesa anterior: la citada Crónica de Laon (h. 1219) ${ }^{48}$. Más que una poco probable rela-

$46 D^{\prime}$ este rrey don Pedro beran cuyñados el conte de Tolosa e sus fijos, que sus cormanas auian por mugeres. Et fo el conte de Montfort sobre Tolosa. E este conte de Mont Fort tenia tierra por bonor del rrey d'Aragon. Et fo el mey don Pedro de Aragon en ayuda del conte de Tolosa e de su fijo. E yssio fuera el mrey d'Aragon al conte de Mont Fort e lidiaron anbos. Mato el conte de Mont Fon al mey don Pedro d'Aragon, LIBRO DE LAS GENERACIONES (h. 1260), ed. J. FerRANDIS MARTíNEZ, "Textos Medievales», n² 23, Valencia, Anubar, 1968, p. 63. Véase la gran diferencia entre esta visión "exclusivamente política" de Muret y las explicaciones de las crónicas eclesiásticas francesas más favorables a Pedro el Católico.

$47 \mathrm{El}$ texto completo del Toledano dice: [el rey Pedro\} fuit semper regi Castelle Aldefonso nobili fidei amicicia federatus et cum eo in famosissimo bello Vbete fuit uictor... (...) Hic rex Petrus sab Innocencio Papa III Romam adiens, ab eodem Papa fuit in eccleria sancti Pancratii diademathe caronatus. Denum cum uenerabilis Amaldus Narbonensis antistes contra bereticas, qui in prouincia Narbonensi nomen Domini blasphemabant, de Gallits crucis signatorum multitudinem aduocasset, aduenit Petrus rex Aragonum in auxilizm comitis Tolosani, nam ipse Raymundus comes Tolose Alienor sororem Petri regis Aragonensis ducerat in uxorem. Raymundus etiam eius filius, patri equiuocus, sorori regis nomine Sancie... (...) Rex itaque Petrus cum paucis Aragonensibus et pluribus Cathalanis et predicto comite et etiam cum Fuxensi et aliis magnatibus Gallie Gotbice iuxta castrum quod Murellum dicitur cum Gallicis comiserunt, et sicut Domino placuit, rex cum Aragonensibus in prelio cesiderunt, quia ipsi soli uiriliter perstiterunt, Fuxensi et Tolosano comitibus terga prebentibus cum aliquibus Cathalanis (...) Mortuus autem sepultus est in Sexena (...) Occubuerunt ausem cum eo in bello de magnatibus Aragonis Aznarius Pardi et Petrus Pardi filius eius et Gomicius de Luna et Michael Lusia et multi alii de poscioribus Aragonis. Hac prelium fui era MCCLII, RODRIGO JIMÉNEZ DE RADA, lib. VI, cap. iiii, pp. 181-182, lín. 1-38.

Híngania, LX/3, núm. 206 (2000) 947-976 
ción entre ambos relatos, esta coincidencia sugiere la existencia fuera de la Península de una corriente de opinión "cruzadista moderada" - las crónicas de Laon, Auxerre y Trois-Fontaines - que quiso salvar la imagen de Pedro de Aragón distinguiendo entre el problema herético - exclusivo de los occitanos-y el problema político - motor del Juicio de Dios de 1213- como explicación coherente a la intervención armada de un buen rey cristiano contra la Cruzada de Roma ${ }^{49}$.

Respecto del Toledano, hay que pensar que conoció personalmente al rey Pedro y que supo de su ortodoxia, de sus virtudes personales y de su amistad con Alfonso VIII de Castilla, héroe de su obra. Ambos reyes eran parientes entre sí y de otros monarcas peninsulares, de modo que una acusación de herejía sobre el Casal d'Aragó podía salpicar a otras casas hispanas reinantes. Tampoco puede desdeñarse la «hispanidad» de Pedro de Aragón en un autor con una clara conciencia de "comunidad española»so. Por último, si como prelado no podía ocultar la herejía, como dirigente político no podía silenciar una realidad feudal occitana que sólo ignoraban deliberadamente los partidarios acérrimos de la Cruzadasi.

Rodrigo de Toledo halló, por tanto, una solución intermedia entre ortodoxia religiosa — condena de la herejía - y respeto hacia el rey Pedro — argu-

48 CRONICA DE LAON: Eadem verò anno MCCXIII, pridie idus septembris, feria quinta infra octavas Beatae Mariae, commissum est praelizm apud Murellum, quod est castrum non Longe ab urbe Tolosa, inter fideles et becereticos, in quo fideles victoria positi sunt. Petrus itaque venerabilis Arragonensium Rex, qui ut sororio suo fierit in auxilium, Comiti scilicet Tolosano, advenerat, non quòd ipse baereticis faveret, sed, ut dittum, est, bonorem sororii sui defenderet, in ipso praelio occubuit cum magna multitudine suorum; ex parte verò fidelium solus miles cum paucis alizs repertuis est cecidisse. Simon verò Comes Leicestraze et Montisfortis, dux et signifer cbristiani exercitus, fide et armis strenuts, suis quidem victoriam provenisse gaudebat; de morte verò illustris Regis Arragoniace non modicim lamentabatur, sciens ob id maxima dispendia fidelibus fore ventura. Fuit autem Dominus cum fideli suio Comite Montisfortis, omnia ejks opera dirigens, baereticos per manum ejus exturbans et ferè Gotbiam universam infra sex annos ei subjiciens (RHGF, vol. XVIU, p. 716).

19 Sobre estas fuentes, puede verse LE Clerc, V.: *Chronique d'un chanoine de Laon (01219)», Histoire Littéraire de la France, ounrage commencé par des religieux bénédictins de la Congrégation de Saint-Maut, París, 1832, ed. facsímil, París, Librairie Universitaire, 1895, vol. XXI, p. 668; DAUNOU, P.C.F: «Robert Abolant, moine de Sant-Marien d'Auxerre, chroniqueur», Ibidem, vol. XVII, pp. 110-121; y PetiT-Radel, L.Ch.F.: «Albéric de Trois-Fontaines, ordre de Citeaux, auteur d'une chronique qui finit en 1241», Ibidem, vol. XVIII, pp. 279-292.

so "Since he spoke for the Spanish Church, by that test the De rebus Hispanie was the authentic history of Spainm, LINEHAN, P.: History and Historians of Medieval Spain, Clatendon Oxford Press, 1993, p. 353; «...si en todos los reinos se habla de la pérdida y recuperación de una España a la que se siente pertenecer de manera natural, no puede extrañar ya que deba hablarse del sentimiento profundo de comunidad española como algo perfectamente arraigado, al menos entre las gentes cultas de nuestra Edad Media», GoNZÁLEZ ANTÓN, Españă y las Españas, p. 128.

${ }^{51}$ Como no la ocultaron las citadas crónicas moderadas de LAON, AUXERRE y TROISFONTAINES. RODRGO DE TOLEDO conocía la Europa del momento tanto como su colega el auror de la CRÓNICA LATINA: si no dejó constancia de ello era porque su «campo de trabajo» se restringía a la historia hispánica y, en el caso de la batalla de Muret, porque no le inceresaba. 
mentación oficial sobre Muret-. Al hacerlo dio un paso más en el camino apuntado por los "cruzadistas moderados» e iniciado ya antes por su paisano el "ambiguo" Guillermo de Tudela: todos distinguieron entre «problema religioso» y «problema político»; todos vieron necesaria la Cruzada, pero todos también creyeron justas las razones que habían llevado a Pedro el Católico hasta las murallas de Muret $^{52}$.

c) La versión catalano-aragonesa del Toledano: los Gesta Comitum Barcinonensium II y III (h. 1266-1314)

La relevancia de este relato estriba en su conversión en verdadera "versión autorizada» de la Cruzada Albigense. La razón fue el prestigio de la obra de Rodrigo de Toledo como la más importante "Historia de España» escrita hasta la fecha en todo el ámbito cronístico peninsular ${ }^{53}$.

Ello explica que su versión ortodoxa, historiográfica, eclesiástica, «legitimista», exculpadora y conscientemente incompleta de la Cruzada Albigense pasara a la Corona de Aragón como interpretación «oficial» de los sucesos de $1213^{54}$. En los Gesta Comitum Barcinonensium II —redacción catalana (1267-1299)-y

52 La voluntad de exculpación demostrada por RODRIGO DE TOLEDO se proyectó con fuerza en la historiografia española de la Época Moderna. Un precioso ejemplo lo tenemos en la curiosa versión de un conocido cronista del siglo XVII: Algunos bistoriadores se arrojaron sin fundamento a juzgar, que el Rey Don Pedro de Aragon, patrocinaua a las Albigenser: calumnia en que padecen manifiesto engaño; porque si bien es verdad, que en este año passò el Rey don Pedro a defender al Conde de Tolosa, no fue en orden a patracinar los Hereges; sino a favorecer al Conde, que estaua casado con su bermana; y porque el Conde Simon de Monforte molestatua sus sierras, fue en persona a socorrerle: y teniendo noticia el Sumo Pontifice Inocencio, que el Rey Don Pedro estaua cerca, le embiò a llamar, y le coronò, y mandò argir por mano del Obispo Portuense, $y$ le armò Caxuallero en la Iglesia de San Pedro, dandole priuilegio, que de alli adelante los cordones de todas las Bulas fuessen de los colores de oro, $y$ rojo, que son las A maas de Aragon, como al presente se usan: de que bazen mencion Zobio, Fray Gauberto Fabricio, Beuter, Zurita, Mariana y otros. Tadas estas demostraciones que bizo el Pontifice con el Rey Don Pedro, son bastante prueba de no ser cierto lo que se le imputa, de auer amparado a los Herejes: y el renombre que consiguiò de Catolico, es muy contrario a esto, ALONSO NúNEZZ DE CASTRO, Corónica de las señores Reyes de Castilla don Sancho el Deseado, don Alonso el Octavo y don Enrique el Primen, Madrid, Pablo de Val, 1665, "Coronica del rey Don Alonso de Castilla", cap. lviii, fols. 216-217.

33 La parte de historia antigua fue traducida al catalán por PERE RuBERA De PERPINYà bajo el título de Croniqua de Espanya (h. 1266). En el resumen correspondiente a la historia "contemporánea», este autor mantuvo la interpretación política de la batalla de Muret vigente desde principios de siglo: [Pedro el Católicol $E$ a la profi ajuda al Comte de Tholosa contra los frangesos $E$ assetja lo Castell de Morell $E$ aqui fo mon en lany de nostro senyor. Mcoxij (ed. J. MAssó TORRENTS, «Historiografía de Catalunya en català durant I'epoca nacional», Revue Hispanique, XV, 1906, pp. 485-613, esp. p. 500). En Castilla y León la obra del Toledano fue, como veremos, el eje vertebrador de la cronística oficial en castellano de finales de siglo. Fue también una fuente esencial para las historiografías oficiales de Portugal (primer tercio s. XIV) y Navarra (s. XV).

54 Así fue por decir del rey Pedro eque era plene catolicum: que havia acudit a la lluita affinitatis debito, vindicació que havia de passar a les nostres cròniques $\mathrm{i}$ havia $\mathrm{d}$ 'esdesvenir-hi clàssica», COLL i ALENTORN, M.: «Roderic Ximenez de Rada i la nostra historiografia», reed. en Historiografia, Barcelona, Curial Edicions Catalanes, 1991, pp. 114-117, esp. p. 115. 
III -redacción latina final (1303-1314)-, los monjes de Ripoll tradujeron al Toledano y lo combinaron con la versión compuesta por ellos poco después de la batalla, elaborando uno de los más completos relatos de Muret pese a sus limitaciones intrínsecas.

Así, de la segura mano del arzobispo de Toledo la corte de los reyes de Aragón reconoció por primera vez la existencia de la herejía, condenándola en una evidente demostración de ortodoxia. No olvidó, sin embargo, la lealtad del rey Pedro a la Iglesia y al Papa, ni sus derechos en las tierras occitanas, como tampoco dejó de repetir que la guetra se debió a los ataques de Simon de Montfort contra los condes de Tolosa casados con las hermanas del rey ${ }^{55}$.

Dos datos interesan especialmente de esta versión. El primero es la ansiosa insistencia en aclarar la ortodoxia de Pedro el Católico:

...ista solum \& non alia ratione venit in auxilium dicti Comitis Tolosani \& sororum suarum apud castrum de Murels6.

Tal énfasis revela hasta qué punto fue sentida en la Corona de Aragón la necesidad de lavar ante el resto de la Cristiandad la deteriorada imagen del rey muerto en Muret.

El segundo es consecuencia de esta urgencia y se trata de la única novedad introducida por los Gesta II y III respecto a versiones anteriores: la derrota no fue un castigo divino, pues no había complicidad con la herejía; no cabía culpar al monarca en una crónica oficial de la Corona ${ }^{57}$; tampoco, por tanto, a sus tropas, aunque Rodrigo de Toledo sí hubiera acusado directamente a los catalanes. Desde mediados del siglo XIII, los culpables del desastre tuvieron nombres propios:

55 GESTA COMITUM BARCINONENSIUM ET REGES ARAGONENSIUM III: ...Amaldus Archiepiscopus Narbonensis plures crucesignatos de Francia adduxisset in provinciam Narbonensemb contra baeraticos qui in illis partibus morabantur et, blasphemantes nomen Christi, contra fidem public̀ proedicabant, dictus Dominus Rex, mandato Domini Papae, cui obediens fuit semper, tradidit Carcassonam et alia castra cum earum dominio Simoni comiti Montisfortis, recepto bomenatge et fidelitate ipsiur. Verum cum comes praedictus insurrexisset contra comitem Tolosanum et sorores dicti domini Perri et eos exberedaret, et multis precibus et munitionibus interiectis ex parte dicti domini negis, et adbuc, quod plus est, eidem comiti super baec mandato domini papae facto, cessare nollet a damno et iniuria dicti comitis Tolosani... (pp. 53-54; redacción catalana, GESTA $H$, pp. 140-142).

56 Inmediatamente, el cronista copia las palabras de Rodrigo de Toledo que reiteran la inocencia del rey caído ante la Cruzada: Dominus Rex Petrus venerat ad partes illas causa praestandi auxilium tantum suis saroribus, ut praedicitur, \& Comiti Tolosano, non ut daret auxilium alicui infideli seu Christianae fidei inimico, in qua ipse fidelis multim extiterat \& sine omni scrupulo apud Deum.

37 Como sucesión de hazañas militares de los "condes-reyes" catalano-aragoneses elaborada por autores stoujours prêt à dorer le blason de la maison comtale de Barcelone, en remémorant les hauts faits de ses membres» (AURELL, «Autour d'un débat historiographique», p. 17), la intención primera de los Gesta era exculpar al rey Pedro. 
Los comtes de Tolosa e de Fox ab lurs fugiren e lexaren al camp lo dit rey, ab gran desonor, $d$ 'on son e seran en gran blasme perpetual.

Concluía así el camino iniciado en Castilla por el Toledano: de la derrota de 1213 fueron responsables los condes occitanos, aquéllos a quienes Dios, el papa y el rey de Francia se habían encargado de estigmatizar como herejes. Por su cobardía en la lucha, su ya tradicional filiación con la herejía y, quizá, su condición de foráneos, los vituperados condes de Tolosa y Foix se convirtieron en la perfecta «cabeza de turco» de los tristes sucesos de la batalla de Muret.

En consecuencia, desde finales del siglo XIII y principios del XIV esta versión castellano-catalana, eclesiástica, historiográfica, ortodoxa, exculpadora, legitimista y antioccitana de los Gesta Comitum Barcinonensium II y III se convirtió en la interpretación "oficial» de la Cruzada Albigense en la Corona de Aragón ${ }^{58}$. Con algunos añadidos seguiría viva durante toda la Baja Edad Media, aunque no en solitario.

s8 Esta visión se mantuvo en crónicas tardías como la Crónica de San Juan de la Peña (1369. 1372) del rey PEDRo El CEREMONIOso: $E$, encontinent, lo comte de Tolosa e de Foix fugiren. $E$ lo dit rei, volent mas morir ab bonor que viute ab desbonor, per tal car null semps en batalla que fos no girà car mort en aquella (ed. catalana A.J. Soberanas, Crònica general de Pere III el Cerimoniós dita comunament Crònica de Sant Joan de la Penya, Barcelona, 1961, cap. XXXIV, p. 115); la Grant Coronica de los Conquiridores (h. 1362?) del Maestre del Hospital JUAN FERNANDEZ DE HEREDIA: ..por la qual razon et guerra el rey don Pedro murio enla batalla de Muriel, enla qual to desempararan et fuyeron el conde de Tolosa et el compte de Fox qui eran conel (ed. parcial G.U. UMPHREY, «Aragonese texts now edited for the first timen, Revue Hispanique, XVI, 1907, pp. 244-287, esp. p. 286); la Cbronica (1380) de JAUME DOMÉNECH: [los cruzados] irruenter in exercitum comitibus Tholose et Fuxi ut fere omnibus regem deserentibus, rex cum paucis remanens mori pacius voluit quem terga dare (ed. P. LÓPEZ ELUM, «Textos Medievales", 42, Valencia, Anubar, 1975, p. 80); las Histories $i$ Conquestes dels Reys d'Arago i Comtes de Catalunya (1438) de PERE TOMIC CAULLER: $e$ aqui lo dit Rey mori en una batalla que bague ab los del dit Comte molt desastradament a gran culpa del Comte de Foix, qui nolio corregue, en l'any. M.c.c.xiii. segon serix lo Archabisbe toleda (ed. A. UвiEto ARTETA, «Textos Medievales", 29, Valencia, Anubar, 1970, p. 81); la Cbronica d'Espanya (1493-1513) de Pere MiQuel Carbonell: e fo la batalla tan gran que los comtes de Tolosa e de foix veents $e$ altres de llur compaya que lo rey de Arago tenia lo pijor de la batalla meter en se en fuyta e desemparar en aquell (Barcelona, C. Amorós, 1546, fols. lix-lx) y la Chronica Regum Aragonum et Commitatum Barcbinonae et Populationis Hispaniae (1495-1519) del valenciano ESTEBAN ROLLAN (ed. $M^{2}$.I. FalCón PÉREZ, "Textos Medievales», 76, Zaragoza, Anubar, 1987, cap. XXIX, p. 46).

La vitalidad de esta interpretación se comprueba viéndola repetida siglos más tarde en la Histaria General de España (186I) del célebre historiador Modesto LAFUENTE: «El rey de Aragón salió á encontrarlos con sus escuadrones: mas al primer encuentro los condes herejes ó fautores de la herejía volvieron vergonzosamente la espalda; los católicos atacaron entonces con intrepidez al escuadrón en el que estaba el monarca, é hiciéronlo con tal ímperu que el vencedor de las Navas de Tolosa perdió allí miserablemente la vida con muchos de los valientes que le habían acompañado en aquella gloriosa jornadaw (vol. III, Barcelona, 1888, lib. II, cap. xi-xii, pp. 337-356 y 359-374, esp. p. 376). 
d) La «revisión castellana» del Toledano: la Estoria de España de Alfonso X el Sabio (h. 1270-h. 1312)

En estos mismos años, el rey de Castilla-León Alfonso X el Sabio (12521284) y sus sucesores patrocinaban una gran Estoria de España, proyecto historiográfico inacabado que sobrevive parcialmente en la Primera Crónica General de España (h. 1270-1289) y, entre otras, en la Crónica de Veinte Reyes (h. 12891312)-. La fuente principal de esta historia fue la magna obra de Rodrigo de Toledo. Su versión «oficial» del reinado de Pedro el Católico y de Muret se proyectó así en la cronística castellana..., pero no literalmente ${ }^{59}$. Los cronistas alfonsíes modificaron el sentido que el arzobispo había dado a la derrota de 1213:

Et maguer que el rey don Pedro era buen cristiano, pero que uiniera en ayuda del conde con quien auie debdo a deffender los hereges que son yente sin Dios, quiso Dios que muriesse y assi como dixiemos ${ }^{60}$.

El epílogo exculpador de Rodrigo de Toledo había perdido su eficacia en la Castilla de finales del siglo XIII: la muerte de Pedro el Católico volvió a ser contemplada como un castigo divino a su alianza con los herejes.

Esta revisión prueba el alejamiento del cronista alfonsí respecto de los protagonistas de la Cruzada, pero también algo mucho más relevante. Hay que tener en cuenta que los compiladores alfonsies no utilizaron la Crónica Latina, olvidada casi hasta nuestros días, y sí, en cambio, la prestigiosa De rebus Hispaniae. Sin embargo, su condena del rey Pedro recuerda más la visión «cruzadista» y coyuntural del obispo anónimo que la versión política e historiográfica del Toledano. Ello sugiere una interesante hipótesis: junto a la visión "solidaria» con la buena imagen de Pedro de Aragón, en la Castilla del siglo XIII sobrevivió otra «corriente de opinión» mucho más ortodoxa y militante en favor de los objetivos de la Cruzada Albigense.

99 Alfonso X El SABIO, Primera Crónica General de España (h. 1270-1289), ed. R MEnÉnDeZ PIDAl y D. CATALAN, Madrid, 1977, cap. 797, pp. 478-479; y CRÓNICA DE VEINTE REYES (1270-1312), ed. y esc. M. Alvar, G. Martínez Díez, F. Fradejas, F.M. Ruíz Asensio, C. HeRNÁNDEZ, Burgos, 1991, lib. XIII, cap. XXXVUI-XIVIII, pp. 287-292 y lib. VII, caps. 13-14, pp. 156-158. Sobre la compleja historiografía alfonsí, véase CATALAN, D.: La *Estoria de España* de Alfonso X. Creación y Evolución, Madrid, Fundación Menéndez Pidal-Universidad Autónoma de Madrid, 1992.

60 El relato completo dice así: [Pedto de Aragón intervino] en ayuda del conde de Tolosa. Et esse don Remont conde de Tolosa era casado con donna Leonor bermana desse rey don Pedro de Aragón. Et el rey don Pedro con unos pocos de aragoneses et con muchos de los catalanes en uno con el dicho conde de Tolosa, et atun con la yente de los Fuxenes [Foix] et otros altos onnes de la Francia Gotica que le uinieron en ayuda al rey don Pedro et al conde de Tolosa pora deffender dell arsobispo las bereges, ouieron su batalla con los franteses cercal castiello que a nombre Munell. Et contescio assi por plazer de Dios, ca otra guisa non padrie ser, que murio y el rey don Pedro con Las aragoneses en aquella batalla, ca ellos solos lidiaran muy esforçadamientre et fincaron en el campo en la lid; et el conde de las Fuxenes et el conde de Tolosa, en uno con algunos de los catalanes, touieron sus espadas et condesaronlas bien et fuxieron (Primera Crónica General, cap. 797, p. 479).

Hisponia, LX/3, núm. 206 (2000) 947-976 
Hasta el tercer cuarto de siglo, esta perspectiva «religiosa» quedó oscurecida historiográficamente por la simpatía y lealtad que Rodrigo de Toledo quiso y supo manifestar en su breve relato sobre el rey Católico. Su prestigio dejó en segundo plano un "extremismo" que debían compartir muchos dirigentes castellanos, sobre todo entre el alto cleto - tal como demuestra la Crónica Latina-. La reaparición de esta postura en la cronística oficial de Alfonso X prueba su supervivencia en silencio.

Con su autoridad y crédito, Rodrigo Jiménez de Rada pudo imponer en la historiografía hispana su peculiar versión de la Cruzada Albigense, pero no impedir el regreso de la visión de la batalla de Muret como un castigo de Dios. A finales del siglo XIII el arzobispo de Toledo ya no vivía para defender la buena memoria del rey Pedro de Aragón ${ }^{61}$.

La «revisión» realizada en época de Alfonso el Sabio se mantendría apenas sin cambios durante toda la Baja Edad Media ${ }^{62}$.

e) El olvido de Occitania: la «versión oficial» de Jaime I de Aragón (h. 12441276)

El recuerdo de la Cruzada Albigense evolucionó de forma más compleja en la Corona de Aragón durante la segunda mitad del siglo XIII. Al calor de la

61 No puede desdeñarse esta condena de Pedro el Católico como demostración coyuncural de ortodoxia por parte de la corte de Alfonso X el Sabio. Sin embargo, el testimonio de la CRÓNICA LATINA sugiere la existencin en Castilla de una postura antiherética estable y no meramente circunstancial. Sobre la herejía en época alfonsí, véase MrTRE FERNÁNDEZ, E.: «Hérésie et culture dirigente dans la Castille de la fin du XIIr siècle. Le modèle de Alphonso X", Heresis, 9 (1987), pp. 33-47; e idem, "La cultura antiherética en Castilla en tiempos de la crisis cátara (de Martín de León a Alfonso X)», Conferencia presentada en el Cologuio "Le Catharisme, nouvelles recherches, nouvelles perspectives", Centre d'Études Cathares, Carcassonne, 20 de agosto de 1998.

62 Un buen ejemplo es el resumen de la Estoria de España del vasco LOPE GarCíA DE SALAZAR en su Libro de las Buenas Andanzas e Fortunas (h. 1471-1475): Muerto este don Remón Reynó s fijo don Pero, segundo deste nonbre e VIJ Rey de Aragón e de Varçelona. E en el su Reynamjento vino el Arçobispo don A maldo de Narvona con muchas gentes crusados por el Santo Padre sobre los frisones [=occitanos] que eran dados por erejes en el grand Congilio de Cleramont. Eran en ayuda destos erejes este Rey don Pero e don Remón Conde de Tolosa, e mastrando Dios su justiz̧za fueron vençidas los erejes e muertos este Rey don Pero e otros muchos de los de su partida; e fuýa el Conde de Tolosa e presos e muertos mucbos de los suyos. E fue destruydo aquella eregia (ed. A. Rodríguez Herrero, 4 vols., Bilbao, Diputación de Vizcaya, 1967, vol. III, libro XIX, pp. 356-357).

No ocurriría lo mismo, sin embargo, entre los historiadores españoles posteriores. El citado ALONso NúṄEZ DE CASTRO (s. XVII) encarna, como vimos, el espíritu exculpador heredado del arzobispo Rodrigo de Toledo: Los Reyes de Aragon, y Francia tutieron alteracion por esse tiempo; la causa fue, que los Condes de Tolosa, padre y bijo, estauan casados con D. Constansa, y Doña Dulke, bemanas del Rey Don Pedro de Aragon. El conde de Monforte bazia crueles bostilidades a las de Tolasa, diziendo eran Caudillos de los Henjes Albigenses: el rey Don Pedro acudio con grueso exenito contra el Conde, porque destruia los patrimonios, y tierras de sta bermantar, y ckñados; pero despues le mataron en Francia en ena sangrienta guerra sus contravios; fue sepultado su cuerpo en el convento de Xigena de Aragon, que es de La Orden de San Iuan (Corónica de los señons Reyes de Castilla don Sancho el Deseado, don Alonso el Otraso y don Enrique el Primero, Madrid, Pablo de Val, 1665, «Coronica del rey Don Alonso de Castilla», cap. lxxiii, fols. 263-264).

Hispania, LX/3, núm. 206 (2000) 947-976 
gran cronística catalana, se observa en esta época la existencia casi simultánea de hasta tres relatos diferentes de la batalla de Muret como resúmenes interesados de la Cruzada.

El primero es el citado de los Gesta Comitum Barcinonensium II-III.

El segundo es la original versión de Jaime el Conquistador (1213-1276), hijo del rey Pedro, en su Llibre dels Feyts (h. 1244). Se trata de una autobiografía que ofrece "una interpretación oficial, la que deseaba que quedase registrada” de la historia de sus reinos, incluida la derrota y muerte de su padre. ${ }^{63} \mathrm{Co}-$ mo los autores occitano-catalanes coetáneos, ignora la herejía y la Cruzada, pero también los argumentos familiares vigentes en toda la Península desde 1213. Por contra, acentúa la interpretación antioccitana de los Gesta II-III al

63 JAIME I, Llibre dels Feyts (h. 1276): E, passat lo temps del nostre naiximent, En Simon de Montfort, qui tenia la serra del Carcassès, e de Bederrès, et en Tolosà ço que bi bavia guanyat lo rei de Franģa, volc bater amor ab nostre pase; e demana-li que ens lliutris a ell, car ell nos nodriria. E ell fia's tant en ell e en la sua amor, que lliwrd ad ell nbs per nodrir. $E$ nós estant en son pader, les gents d'aquelles terres, que dessús batem dites, vengren a nostre pare e dixeren-li que ell padia ésser senyor d'aquelles terres, si ell les volia penre $i$ emparar. E el rei En Pere nostre pare era franc e piador, e ab la pietat que a ell pres d'ells, dix que se $n$ 'empararia: $e$ enganowen-lo ab belles paraules. $E d$ 'zna part li bo daven de paraula, e d'altra part lo bo tolien per obra; car nós oïm dir a En Guillem de Cervera, e a N'Amas de Castellbo, e a En Dalmau de Creixell e a altres qui eren ab ell, que li deien: aSinyer, veus nostres castells e nostres viles: emparats-was-en, e metets-bi vastres batllers. $E$ quan ell bo volia emparar deien-li: aSenyer, com gitarets nostres mullers de nostnes maisons, mas nós e elles ne serem vossnes, e en farem vostra volentats. E per aquesta manera no li atenien ne que li promesessen. $E$ mostraven-li llurs mullers, $e$ llurs filles, e llurs parentes les plus belles que podien trobar. $E$ quant sabien que ell era bomne de femnes, tolien-li son bo propdsit e feïen-Lo mudar en gुo que ells volien. $E$ quant les noves serien llongues de contar, a les cases canes que hi foren, no en volem pus parlar.

En Simon de Montfort era en Murell be ab vuit-cents bomens a cavall entro en mill; e nostre pare venc sobre ell prop d'aquell lloc on ell estava. E foren ab ell d'Aragó don Miquel de Lásia, e don Blases de Alagó, e don Rodrigo de Licana, e don Ladró, e don Gomes de Lana, e don Miquel de Rada, e don Guillem de Puyo, e don Agnar Pardo, e d'altres de sa mainada molts, e d'altres qui a nós no paden membrar; mas tant nos membre que ens dixeren aquells que bi avien estat, e sabsen lo fait, que lleva don Gomes, e don Miquel de Rada, e don $A_{\text {gnar }}$ Pardo e alguns de sa mainada que bi moriven, que ells altres 10 desampararen en la batalla, es'en fuginen: eforen-bi de Catalunya En Dalmats de Creixell e N'Hug de Mataplana, e En Guillem d'Horta, e En Bemat de Castellbisbal, e aquelles fugiren ab les altres. Mas bé sabem per cert que don Nuno Sanxes, a En Guillem de Montcada, que fo fill d'En Guillem Ramon e de Na Guillema de Castellsi, no foren en la batalla, ans enviaren missatge al rei que els experis, e el rei no els volc esperar: e fen la batalla ab aquells qui eren ab ell. $E$ aquell dia que féu la batalla bavia jagut ab una dona, es que nós oïm dir depuis a son reboster, qui bavia nom Gil, e fo puis frane de l'Espisal, qui havia estat en aquell consell, e altres qui bo viren per sos ulls, que anc a l'Evangeli no poc estar en peus, ans s'assec en son seti mentre es deïa. $E$ ans que fos la batalla volia's metre En Simon de Montfort en son poder per fer sa volentat, e volia's avenir ab ell; e nostre pare no bo volc pendre. $E$ quan viren acò lo comte Simon e aquells de dins, preseren penitencia, e reeberen lo cas de Jesucrist, e dixeren que més amaven morir al camp que en la vila. $E$, sobre aģò, eixinen combatre ensems en una. $E$ aquells de la part del rei no saberen rengar la basalla ni anar jussats, e ferien cada un ric bom per si, e ferien contra natura d'armes. E per lo mal ordonament, e per lo pecat que era en ells, bac-se a vengre la batalla, e per la mercè que no bi trobanen aquells qui eren de dins. E aquí mori nostre pare; car aixi no ba usat nostre llinatge tots temps, que en las batalles que ells han feites ne nós farem, de vengre o morir (ed. F. SolDEvlLA, Les Quatre Grans Cròniques, Barcelona, 1971, caps. VHL-X, pp. 6-7). Cita de HOMET, R: «Caracteres de los político en el Llibre dels Fets de Jaime el Conquistador», Res Gesta, 32 (enero-diciembre 1993), pp. 171-194, esp. pp. $175-177$. 
hacer de la «fourberie des languedociens» —oferta de tierras y mujeres a cambio de ayuda militar - la causa de la guerra contra Simon de Montfort ${ }^{64}$. Este, además, es elogiado por sus virtudes, lo que quiebra la tradición antifrancesa de la cronística de la Corona de Aragón y es un caso único entre los autores hispanos con la excepción de Guillermo de Tudela y la Crónica Latina castellana.

Su explicación del desastre fue también inédita: no hubo "traición occitanas sino impaciencia, confianza y graves pecados (codicia, soberbia y lujuria) en el rey Pedro, así como mal ordenament en sus caballeros, razón militar muy verosímil apuntada ya en los Gesta $I$. De esta última fuente Jaime I tomó también el elogio a la digna muerte de su padre en combate, verdadera divisa del Casal d'Aragós'.

Esta original versión de Muret, tan favorable a los vencedores de la Cruzada -el Papado y el rey de Francia-, puede considerarse consecuencia coherente de la política occitana de Jaime I culminada en el Tratado de Corbeil (1258), una política tachada de «abandonista» que ha de entenderse como una actitud realista ante la dura disyuntiva planteada por los hechos consumados derivados del Tratado de Meaux-Paris (1229) -legítima y factible expansión sobre el Islam peninsular frente a una ilícita e incierta guerra con el Cristianísimo rey de Francia por la defensa de sus tierras y derechos occitanos- ${ }^{66}$.

En última instancia y a nivel historiográfico, puede plantearse que para Jaime el Conquistador la batalla de Muret acabó siendo una verdadera sentencia divina con evidentes consecuencias políticas ${ }^{67}$.

f) La «versión épica» de Muret: Bernat Desclot y la follia del rey Pedro (h. 1284-1288)

Hay todavía un tercer relato sobre 1213 , concretamente en la segunda crónica catalana titulada Llibre del Rei En Pere - Pedro el Grande- de Bernat Desclot (h. 1284-1288). Este autor era servidor real, de modo que se trata de otra versión «oficial» de los sucesos de Muret.

Su relato es muy próximo a los hechos, pues deriva de la prosificación de un poema juglaresco catalán compuesto quizá por un contemporáneo de la bata-

64 La expresión es de Aurel., "Autour d "un débat historiographique», p. 12.

65 E aquells de la part del rei no saberen rengar la batalla ni anar justats, e ferien cada un ric bom per $s i$, e ferien contra natura d'armes (...) $E$ aqui mori nostre pare; car aixi no ba usat nostre llinatge tots temps, que en las batalles que ells ban feites ne nór farem, de vengre o movir. En los GESTA I se dice: et maluit mori in bello quam si uiuus exiret de campo (pp. 17-18).

66 Este «abandonismon fue rebatido por Archibald R. LEwIS al asegurar que Jaime I buscó un dominio «indirecto" de Occitania y no directo como su padre ( «Jaume the Conqueror, Montpellier and Southern France, 1208-1276», Medieval Society in Soutbers France and Catalonia, Londres, Variorum Reprints, 1984, XVI, pp. I-16; reed. BURNS, R.I.: Los mundos de Alfonso el Sabio y Jaime el Conquistador. Razón y fuerza en la Edad Media, Valencia, Ed. Alfons el Magnànim, 1990, pp. 159-178).

67 La *option occitane est condamnée, du même coup, par la défaite militaire», AURELL, "Autour d'un débat historiographique», p. 12. 
1la. ${ }^{68} \mathrm{El}$ autor ignora la herejía y presenta los combates confusa y parcialmente, aunque con datos muy exactos, esto es, de forma muy similar al continuador tolosano de la Canso de la Crozada (1213-1219) ${ }^{69}$. También silencia el argumento familiar «oficial», aunque Desclot cita una relación de tierras occitanas entonces bajo soberanía del rey Pedro de Aragón ${ }^{70}$. No parece, sin embargo, un gesto «irredentista» sino más bien la expresión del contexto político que envolvió el choque contra los franceses de principios de siglo, una realidad que Desclot revivía a gran escala como testigo y cronista de la guerra de la Corona de Aragón con Francia que culminó en la invasión de Cataluña por el rey Felipe III el Atrevido en 1285 .

El autor reduce la batalla a un breve combate heroico entre el rey y varios caballeros franceses. La culpa del desastre reside así en la follia o "coratjosa temeritat» (Ferran Soldevila) del rey, argumento que puede representar un paso más en el proceso de auto-inculpación iniciado por Jaime I a propósito del traumático «recuerdo de Muret ${ }^{71}$.

6r Bernat Desclot, Crònica o Llibre del Rei En Pere (h. 1284-h. 1288), ed. F. SOldevila, Les Quatre Grans Cròniques, Barcelona, 1971, cap. VI: «En qual manera morí lo rei en Pere d'Aragó, qui fon en la batalla d Ubeda", pp. 414-415; idem, "Un poema joglaresco catala sobre la batalla de Muret", Homenatge a Carles Riba, Barcelona, 1954, pp. 322-325; reed. Cronistes, joglars i potes, Barcelona, Pub. de 1' Abadia de Montserrat, 1996, pp. 303-306.

69 CANSO DE LA CROZADA, \&\& 132-141. Dice DESCLOT: Diu lo comde que, quan lo rei En Pere fo vengut de la batalla d'Úbeda e el rei commençà guerra ab francès, ab lo conte de Tolosa qui $l i$ "'ajudà, e anà-se 'n ab gran cavalleria de catalans ed' aragoneses a Tolosa. E prop de Tolosa encloïren en un castell, que bavia nom Morel, un comte frainces, que bavia nom comte de Montfort e era bom del ret En Pere d'Aragó, be ab tres-cents cavallers. E el rei atendà's aquí entorn del castell volgrense retre a mercè e el rei no els volc pendre a merrè sino per fer sa volentat. Sobre aç̀ aquells del cartell bagren lur consell e dixeren que més llur valia morir combatent que si aquí morien vilment. -»Barons -dix lo conte qui era al castell-, nós bo farem així: armem-nos tots, mas los conalls sien desamats. $E$ quan vendrà sus al matí que ells seran desarmats e seran venguts de les guaites e dormiran desospitadament, e nôs tots plegats davallem del castell, e pensennos-en d' anar; que abans que ells se sien armats ne sien muntats a cavall, serem nós llany». Tot enaixi com bagren dit, bo feeren, Quanc venc al matí a sol ixent, comengaren a eixir del castell tots plegats en lluss cavialls, e pensaren de bracar ed'anar. Quan cells de la bast bo viuren, meseren mans a cridar: «A armes, cavallers! Que els cavillers del castell s'en van'» $E$ el rei, qui asjo bat entes, va pendre ses armes, e muntà a cavall e comengà a córrer apres d'ells: e no foren pus de vint cavallers ab ell, que els altres cavallers ne eren tantost aparellats (pp. 414-415).

70 Aquest rei En Pere destrenya gran terra, so és saber lo regne d'Aragó, e tota Catalunya, e Carcassès, $e$ Bederès, e Montpesller e tota Proença aitant com de l'Emperi era (p. 415 ).

${ }^{71} E$ el rei era molt bon cavaller e coratjos e era molt bé encavalcat, sí que els altres cavallers no podien sant correr com ell; sí que el rei fo molt a davant de sota sa companya e consegui en aquells qui s'en fugien, sí que els fo molt prop, e reginaren-se e conegren que aquest era el rei. -Barons -dix lo comte-, aquest is to rei qui ens encalya, e és molt prous ecoratjos, e nós no li podem escapar en alrra guisa. Tornem a ell, que aixis si som morts. E aixi giraren-se vers ell, e ell fert en ells e, al primer colp, feri un cavaller francés ab la llanģa, e abaté'l mort en terra. Pays vi que la llanga no li valia res, tant era gran la pressa que els franceses li feïen, e mes mans a l'espaa e aqui fés de grans colps, si que ocís tres cavallers abl'espaa; e encara a açò los seus no eren venguts. Sobre aço vengren-li bé deu cavallers justats e anaren-lo ferit, sí que le abateren a terra e aqui mori. Quan viuren que el rei era mort, pensaren-se'n d'anar per cames de cavalls. Quan la companya del rei vengren, trobaren lur senyor mont e no bagren cura de l'encalgar, e feeren molt gran dol aqui sobre llur senyor, e aporta- 
Puesto que el objetivo de Desclot era honrar a la dinastía catalanoaragonesa, para Muret no le servían las crónicas eclesiásticas que hablaban de la herejía, ni el Llibre de Jaime I que culpaba al rey Pedro ${ }^{72}$. El viejo poema catalán era, en cambio, una versión inédita, verosímil, cercana a los hechos, aparentemente objetiva y que explicaba el descalabro de 1213 exaltando las virtudes caballerescas del rey derrotado. En realidad, Desclot elaboró una versión tan incompleta y subjetiva como todas las anteriores e incluso mucho más literaria y panegírica. Sin embargo, el «objetivismo» e innegable calidad de su obra le aseguraron un buen porvenir en la historiografía medieval tardía ${ }^{73}$.

\footnotetext{
ren-la-se' $n$ a les tendes. E llevà-se la bost d'aqui e aportaren-se' $n$ lo rei en Catalunya; e soterrà 'l bom molt bonradament a una abadia de dones que ba nom Seixena (p. 415).

$12 \mathrm{El}$ «recuerdo de Muret" de los GESTA COMITUM BARCINONENSIUM responde al deseo de exaltar las glotias de la dinastía real ignorando o silenciando sus fracasos. De forma complementaria aunque diferente, esta memoria dinástica de DEscLOT responde mejot al «miroir d'une conscience généalogique, de la fierté d'appartenir à une lignée dont les membres jouèrent, pour plus d'un siècle, un tôle capital dans la vie politique des principautés de langue d' $\mathrm{C}^{*}$, AURELL, "Autour d'un débat historiographique», p. 15. Sobre este tema, véase GUENÉE, B.: «Les généalogies entre l' histoire et la politique: la fierté d'être capétien, en France, au Moyen Âge», Annaler, Économies, Sacietté, Civilisations, 1978, pp. 450-477, reed. Politique et Histoire au Moyen Age, París, 1981, pp. 341-368.

73 Su influencia se observa en la crónica anónima F $\operatorname{LOS} M U N D l$ (h. 1407, Bibliothèque National de Paris, ms. esp. 11), en la CRONICA UNIVERSAL CATALANA DE 1425 (Biblioteca Universitaria de Barcelona, ms. 82) -vid. COLL I ALENTORN, M., "Les cròniques universals catalans", Boletín de la Real Academia de Buenas Letras de Barcelona, XXXIV (1971-1972), pp. 43-50-, en la CRÓNICA UNIVERSAL CATALANA DE 1427 (BNM, ms. 17.771, fols. 186b-187a); en la Crònica (1430) de Pere Maça (ed. J. Hinojosa Montalvo, Valencia, Universidad de Valencia, 1979, p. 25), en la Coronica de Aragón (1499) de GAUBERTO FABRIClO DE VAGAD (BNM, ms. $1-2352$ y ed. facs. Zaragoza, Cortes de Aragón, 1996, fols. Lxix-Lxxii) y en la Chronica d'Aragon (1500) del también aragonés Lucio Marineo Sículo (ed. facsímil, Barcelona, El Albir, 1974, libro III, fol. xxvii). La relevancia de esta incerpretación fue tal, que con la misma finalidad fue asumida en el siglo XVI por la cronística oficial de la monarquía hispánica. Un precioso ejemplo es el Catbálogo Real de Castilla (h. 1515-1520) del cronista real Gonzalo FERNÁNDEZ DE OvIEDO Y VALDES, cuyo relato de la batalla de Muret dice: En aquella sazón el conde de Tolosa avia guerra con el conde don Simón de Montforte, e el rey don Pedro salio de Roma con su exército contra el dicbo don Simon, al qual vengio en batalla e puso en buyda a todos los franceses que venian en fautor del dicbo don Simón. E sigujendo el alcançe adelantóse tanto de los stryos que sin aver tiempo de le socorrer tomaron sabrel los enemigos e lo mataron (...) [p. 945, nota: Sanct Antonino, argabispo de Flonençia, dize que la batalla en que fue muerto este rey don Pedro de Aragón fue año de millcoxvij e de millcoxviij, pero cuéntalo de osta manera en fator del conde don Simón e muy al wevés de lo ques dicbo, porque dize quel wey don Pedro fatoresçla la parte de los eréticar de Albi e Tolosa. Hallarse a esto en la $3 a$ parte xHistorials en el titulo 19 capitulo $3 \&$ 2], (ed. E.A. ROMANO DE THUESEN, Transcripción y edición del «Catálogo neal de Castilla», autógrafo inédito de Gonzalo Fermández de Oviedo y Valdés, 4 vols., Michigan, Ann Arbor, 1994, vol. II, pp. 944-945). Sobre DEscior y su uobjetividad", veáse ELLIOT, A.G., «'The historian as artist: Manipulation of history in the chronicle of Desclot», Viator, 14 (1983), pp. 195-209, esp. pp. 203-204. Otra opinión en HOMET, R.: «Monarquía y expansión en la historiografía catalana: la crónica de Bernat Desclot", Oriente e Occidente tra medioeso ed età moderna. Studi in Onore di Geo Pistarino, a cura di Laura Baletto (Alessandtia, 1995), Génova, G. Brigati, pp. 479-505.
} 
Consecuencia de todo ello fue la coexistencia desde finales del siglo XIII de dos recuerdos o versiones "oficiales" paralelas de la derrota de 1213 y de la Cruzada Albigense en la cronística de la Corona de Aragón: una memoria bistórica de origen eclesiástico e inspiración castellano-catalana transmitida por los Gesta de Ripoll; y una memoria dinástica nacida y mantenida viva en el seno del Casal d'Aragó a través de las crónicas reales de Jaime I y Bernat Desclot. Ambas tendrían una clara expresión en la notable obra historiográfica del rey Pedro el Ceremonioso (1336-1387)

\section{LA CRUZADA ALBIGENSE DESPUÉS DE 1213: EL SILENCIO Y LA «PAZ»}

Después de todo lo dicho, iqué puede saberse de lo sucedido en la Cruzada Albigense entre la batalla de Muret (1213) y el Tratado de Meaux-París (1229) a partir de la historiografía hispana del siglo XIII?

La respuesta es casi nada.

74 La memoria bistórica de los Gesta III aparece -aumentada- en la Crónica de San juan de la Peña (1369-1372), historia oficial de la Corona catalano-aragonesa redactada en sus tres lenguas vivas (ed. latina A. UBIETO ARTETA, "Textos Medievales», n' 4, Valencia, Anubar, 1961, pp. 139-142; ed. catalana A.J. SOBERANAS, Crònica general de Pere III el Cerimoniós dita comunament Crönica de Sant Joan de la Penja, Barcelona, 1961, cap. XXXIV, pp. 114-115; y ed. aragonesa C. ORCístegui, Zaragoza, 1986, cap. 34, pp. 83-85). La memoria dinástica revela su vigencia íntima en la Crònica autobiográfica del Ceremonioso (1374-1380): éste recogío un sermó llarg e bé ordenat que su abuelo Jaime II (1291-1327) había dedicado a su padre Alfonso IV (1327-1336) en 1323 antes de la conquista de Cerdeña: le recordaba que la bandera de Aragón sólo había sido vencida una vez, per lo rei En Pere, rei d'Arago e senyor de Montpeller, qui per sa follia fon mort a Morell; que llegada la batalla su deber era vencer o morir; y que jamás combatiera sin reunir todas sus tropas (ed. SOLDEvila, Cròniques, cap. I, \& 12, pp. 1009-1010). La batalla de Muret, la única gran derrota del Casal d'Aragó en más de siglo y medio, se convircio así en un «espejo de príncipes" para los miembros de la dinastía; no debían repetit la follia del rey Pedro, ni sus errores militares, pero sí -llegado el caso- su digna forma de morir, encarnación de la divisa de los «condes-reyes» recordada por Jaime I. Sobre esta obra, HOMET, R., «El discurso político de Pedro el Ceremonioson, El discurso político en la Edad Media, París-Buenos Aires, CNRS-CONICET, 1995, pp. 97-115, esp. pp. 101-102 y 107. El fantasma de Muret volvería a aparecer en silencio entre los siglos XIV y XV: primero en una carta que el duque Martín el Humano envió al rey Juan el Cazador (22 diciembre 1392), en la que citó a Alfonso el Casto y Pedro el Católico sin mencionar su política occitana (vid. COLl i ALENTORN, M., «El rei Martí, historiador», Estudis Romanics, X (1962-1967), pp. 217-226; reed. Historiografia, pp. 304313, esp. 310-312); y más clararnente en la sesión del 20 de enero de 1406 de las Cortes de Cataluia celebradas en Perpinyà, donde el mismo Martín el Humano, ya rey, repitió a su hijo Martín el Joven las palabras de Jaime II, aunque suprimiendo la parte relativa a Muret (ed. R. ALBERT y J. Gassiot, Parlements a les Cortes Catalanes, "Els Nostres Classics», n 19-20, Barcelona, Barcino, 1928, pp. 70-71). Este silencio consciente podría deberse a la crisis que padecía entonces la Corona de Aragón, coyuntura en la que no era conveniente recordar una lejana derrota que empañaba el prestigio de la dinastía. Este último texto fue reproducido íntegramenre en la Chronica d'Espanya (1493-1513) del tardío Pere Miquel Carbonell (ed. Barcelona, C. Amorós, 1546). 
Tras la muerte del rey Pedro la actividad catalano-aragonesa en tierras occitanas remitió poco a poco pese a las insistentes llamadas de socorro de los trovadores a su hijo Jaime $\mathrm{I}^{75}$. Éste se negó a defender «directamente» sus derechos, sellando así el destino francés del espacio occitano y enterrando para siempre la efímera "Gran Corona de Aragón" hispano-occitana que su padre rigió durante sus últimos meses de vida ${ }^{76}$.

Así pues, si puede decirse que 1213 es una fecha fundamental en la historia de la Cruzada Albigense y de toda la Europa meridional, desde un punto de vista historiográfico supone una ruptura definitiva.

De todos los cronistas hispanos de los siglos XIII, XIV y XV, sólo uno narró el destino de la Cruzada tras la devolución de Jaime I a sus naturales en 1214. No puede sorprendernos que se trate del exaltado autor de la Crónica Latina de los Reyes de Castilla, el más «cruzado» de todos los autores de la Espanba del siglo XIII. Lo que narró fue la victoria real francesa sobre el conde Ramon VII de Tolosa en $1229^{77}$.

75 Dice GHL: «Décidément, ce roi aragonais enflammait les immaginations des troubadours à l'époque à un point que peut-être aucun autre personnage politique (le comte de Toulouse y conpris) $n$ 'avait réussi à atteindre. $C^{\prime}$ est qu'il représentait probablement la clé de voûte de cet échaufaudage fantasmatique visant une entité politico-morale occicane (c $c^{\prime}$ est à dire, non-frangaise) dont les troubadours des années quarante semblent avoir rêvé avec une intensité qui frise l'hallucination» ( $L$ 'Age de Parage, p. 266). Véase también NicolAu D'OLWER, Ll.: "Jaume I y los trovadors provensals", "Jaime I y su épocan, I Congreso de Historia de la Corona de Aragón I, Barcelona, 1908-1910, pp. 389-407; y RuQuer, I. de: «Presencia trovadoresca en la Corona de Aragón», Anuario de Estudios Medievales, 26-2 (1996), pp. 933-966.

16 Para el análisis de la historiografia sobre esta polémica cuestión, véase AURELL, «Autour d'un débat historiographique», pp. $20-34$. Su posición, contraria a la posibilidad de una hegemonía catalano-aragonesa en tierras occitanas, tiene contrapartida en ROQUEBERT, M.: «Le problème de au Moye-Âge et la Croisade Albigeoise. Les bases juridiques de l'Etat occitano-catalan de 1213", Annales de l'Institut d'Etudes Occitans (1979), pp. 15-31 y L'Épopé Cathare, vols. II-III. Una revisión del tema en AlviRA, Guerra e Ideologia, II Parte.

$n$ Memoratus autem Lodouicus rex in estate illa... $[1226]$, wenit in partes Prouincie contra bereticos at defensores eorum, de consilio et auctoritate legati Romanae ecclesie, qui tunc uices pape gerebat in partibus Francorum. Venit autem in manu forti et brachio extenso cum exercitu grandi et forti nimis. Cum multis machinis bellicis obsedit ciuitatem famosam Auinionem, que past longam obsidionem reddita est dicto regi et legato supradicto. Subiugata uero fere tota terra illa preter Tolosam et alia castra pauca, dum reuertetur in terram suam, mortuus est in Aluernia. Multi et magni uiri et nobiles, multi mediocres, multi et de minoribus mortui sunt in obsidione predicta. $\langle C>$ omes Tolosanus [Ramon VII] et fauctores ipsius, andita morte domini Lodosici, illustris regis Francorum, repleti gadudio magno ualde, parauerunt se ad reuellandum contra ecclesiam et gentem Francorum, sperantes regis pueviciam et sexum femineum nil magnum agreddi posse. Siquidem dicto Lodouico regi succesit filius Ladouicus, puer tenellus ferme XII annorum, cuius pueri et regni mater, regina scilicet domina Blanca, gloriosi domini Aldefonsi regis Castelle filia, curam suscepit et, tanquam prudens femina, regnum Francorum diu tenuit atque rexit. Habitu igitur diligenti tractatu cum legato ecclesie Romane, qui tunc erat in Francia, et cum arcbiepiscopis et episcopis ceterisque prelatis ecclesiarum et cum baronibus regni mittunt contra comitem Tolosanum et fauctores eius uiros nobiles, strenuos et prudentes cum magna multitudine militum et seraientium, qui, tanquam milites Cbristi et inuicti bellatores, non dantes requiem Tolosanis, totam serram illam, Dei auxilio destitutam, ecclesie Romane, mediante rege Francorum, subdiderunt. Sepedictus siquidem 
¿Por qué lo hizo?

Personal y políticamente, porque fue la reina de Francia Blanca de Castilla - bija del glorioso rey Alfonso [VIII]-, quien sojuzgó a los rebeldes occitanos; historiográficamente, porque en su obra quiso relatar hechos importantes ajenos a la Península; ideológicamente, porque comulgaba con las posturas «cruzadistas» triunfantes en el Tratado de Meaux-París. Su relato termina con estas palabras:

Sic ergo Christus Dominus, Saluator noster, destruxit omnem munitionem aduersum se extollentem. Heretica prauitas, que quasi nidum sum locauerat in terra illa, pro magna parte destructa est, multis hereticis igni traditis aliisque fugatis atque dispersis, quonum dispersio prouidebat Altissimus ne sit occasio subuersionis multorum.

Guardó pues silencio aquella tierra, dijo el obispo-cronista, obtenida la paz de la que careció en tiempos..$^{7}$ Fue la paz, sí, pero la «paz de clérigos y franceses» que tanto lamentaron algunos trovadores occitanos ${ }^{79}$.

Nadie más, sin embargo, se expresó así en la España de los siglos medievales. Para todos los demás cronistas hispanos, la historia de la Cruzada Albigense, sus consecuencias religiosas y, sobre todo, sus decisivas consecuencias políticas murieron con el rey Pedro el Católico en los campos de Muret.

La paz para los vencedores y el silencio para los derrotados. El olvido como último y único homenaje posible al rey muerto por la voluntad de Dios.

comes Tolosanus, widens quod rebellare non posset, supposuit se uoluntati legati et regis Francortu, et in Francia reconciliatus est ecclesie, recepta priws ab eodem cautione sufficienti, scilicet iuramento prestito quod per omnica pareret mandatis ecclerie nec de Francie recederet antequam omnes conditiones, que tunc impleri poterant, impleatsset. Unica filia, quam babebat idem comes [Jeanne], de cuizs matrimonio cum fratre regis Francie tractabatur [Alphonse de Poitiers], deducta fuit ad reginam Francie consobrinam skam, eadem comite moram in Francia protrahente. Anno ab Incamatione Domini $M C C X X I X$, muri Tolose funditus subuersi sunt, et fossata plena sapericiei campi sunt adequata omnesque municiones circumadiacentes dextructe sunt, paucis exceptis quas in manu sua retinuit rex Francorum, CRONICA LATINA, pp. 73-75.

78 Siluit igitur terra, redita sibi pace, cuius expers fuerat temporibus (Lbidem).

79 iAy, viles barones!, bien as tienen atrapados los clérigos y los franceses con su fingida paz [Ai, croi baron, be. ous tenon embregatz clerc e frances ab lor enfaigna patz], TOMIER y PALAIZí, $A$ tomar $m$ 'er enquer al primer us (h. 17 junio 1216), ed. I. FRANK, eTomier et Palaizi, troubadours tarasconnais (1199. 1226)", Romania, LXXVIII (1957), pp. 46-85, esp. pp. 70-72; y ed. RUQUER, Los trovadores, vol. II, cap. LXIV, $\mathrm{n}^{\circ} 231$, pp. 1157-1160, estrofa V. Entre los trovadores antifranceses 0 anticleticales destacaron también Bernart de Labarte, Peire Cardenal, Guilhem Figueira, Bernart Sicart de Maurèjols, Guilhem Rainol d'At, Raimon de Tors, Bertran Carbonel, Berrran d 'Alamanon, Gui de Cavallon, Bonifaci de Castellana, Raimon Escrivan, Guilhem de Montanhagol y Paulet de Marselha. Véase, entre otros trabajos, ZAMBON, F., Paratge: els trobadors $i$ la croada contra els catars, Barcelona, Columna, 1998. 